\title{
THE MANAGEMENT OF THE PATIENT WITH RESPIRATORY INSUFFICIENCY
}

H. B.trRie FAirler, M.B., B.S., F.F.A.R.C.S., and R.A Chambers ${ }^{1}$, M.D., M.R.C.P. ${ }^{2}$

And the Lord God formed man of the dust of the ground and breathed into his nostrils the breath of life. ...

Genesis 2: 7

Althorgh Intermittent P'ositive Pressure (I.P.P.) respiration has been in use since Biblical times ( 1 ), methods of maintaining assisted respiration for prolonged periods were developed more recently. The prolonged use of I.P.P. was considered harmful to the lungs (2) and other methods were preferred (3-6). Of these, the cabinet respirator, in spite of certain disadvantages, achieved the greatest success. This was particularly so in the management of diseases producing muscular paralysis. However, in other conditions in which under-ventilation is a common cause of death, the use of the cabinet respirator was less successful.

In 19.50, during a major epidemic of poliomyelitis, the prolonged use of I.P.P. provided satisfactory (7). This success led to the more frequent use of such techniques, which have been found applicable in a wide range of conditions. This paper presents a review of the management of such conditions, aided by.experience with one hundred consecutive admissions to the Toronto General Hospital Respiratory Unit (8).

For the purposes of this discussion, Respiratory Insufficiency is present when underventilation endangers a patient's life.

\section{Physiological Considerations}

The main function of ventilation is to achieve oxygenation of the arterial blood and to eliminate carbon dioxide. Any depression of ventilation will lower the tension of oxygen in arterial blood $\left(\mathrm{pO}_{2}\right)$ and raise that of carbon dioxide $\left(\mathrm{pCO}_{2}\right)$. However, owing to the form of the oxygen dissociation curve in blood, ventilation must be quite markedly depressed before a fall in oxygen saturation occurs. Thus, a fall in saturation detectable clinically (or a significant fall in content measured manometrically) will not occur until the tension is reduced by nearly 50 per cent (9). Oxygen saturation or content is therefore a poor index of ventilatory efficiency. In contrast, arterial carbon dioxide tension and content show a very quick response to any ventilatory change. In patients with normal lungs and no vascular shunts, oxygenation will always be satisfactory when the $\mathrm{pCO}_{2}$ is normal. The latter is therefore an excellent index of ventilation.

1Present address: Associate Profeshor of Neurology, Seton Hall College of Medicine and Dentistry, Jersey City 4 , New Jersey, U.S.A.

${ }^{2}$ From the Departments of Anaesthesia and Medicine, University of Toronto, and the Toronto General Hospital Respiratory Unit 
Whereas a rise in inspired oxygen levels will improve oxygenation in most instances, even in the presence of respiratory insufficiency, carbon dioxide elimination is entirely dependent upon gaseous volume exchange. Thus, all patients with ventilation below normal will retain carbon dioxide, the effects of which are potentially lethal. To avoid the effects of carbon dioxide retention, the lungs of patients with respiratory insufficiency may be inflated with the necessary additional volume, by I.P.P.

The physiology of intermittent positive pressure ventilation must therefore be examined in an attempt to determine whether assisted ventilation, performed in this way, will produce adequate gaseous exchange and whether it will do so without embarrassing the circulation.

\section{Gaseous Exchange}

By creating a pressure gradient across 1 he walls of the alveoli, positive pressure applied intermittently to the airway results in a flow of air and causes the lungs to expand. The volume of air entering the lung on each inflation will depend upon the pressure exerted (10). Pressures varying from $10-60 \mathrm{~cm} . \mathrm{H}_{2} \mathrm{O}$ above atmospheric, in the upper airway, may be necessary to deliver a normal tidal volume $\left(V_{T}\right)$, depending on the extent of changes in total resistance due to pulmonary lesions. The higher figure is only necessary in rare instances such as severe bronchospasm or diffuse bilateral consolidation.

The adequacy of any given tidal volume will depend, in part, upon the size of the dead space.

Dead Space. The anatomical dead space is the volume of the airway from the point at which no rebreathing occurs down to the terminal bronchioles. While the former point is usually the mouth or nose, once the patient is connected to apparatus the dead space of the latter must be included. This will vary with each machine.

The significant or physiological dead space consists of the anatomical dead space, plus the volume of air entering any alveoli not being perfused by pulmonary capillary blood, plus any air entering perfused alveoli in excess of that necessary to achieve gaseous exchange. Adequate alveolar ventilation $\left(V_{A}\right)$ begins once this dead space $\left(V_{D}\right)$ is filled as shown in the equation $V_{A}=f\left(V_{T}-V_{D}\right)(f=$ resps. per min.). (At tidal volumes less than that of the dead space, the above equation is incorrect [11].)

A given minute volume is, within limits, better achieved by delivering large tidal volumes infrequently rather than the reverse, because of the need to overcome dead space on each inspiration $(1,13)$.

Nomograms are available for the determination of normal minute volumes in individuals in whom the physiological is equal to the anatomical dead space $(14,15)$. In patients with pulmonary lesions causing an enlarged physiological dead space, these figures will provide under-ventilation. This enlargement of physiological dead space is usually due to uneven distribution of inspired air throughout the lungs, causing uneven gaseous mixing.

Distribution. At one time it was believed that a gross distribution defect rendered I.P.P. for prolonged periods unacceptable (2). Although it has recently been con- 
firmed that there is an increase in physiological dead space during I.P.P. (16) and that some mixing defect is inherent in this type of ventilation, it is now realized that this is of minor significance quantitatively.

Diffusion. It has been suggested the I.P.P. may produce a diffusion defect, either by trauma to the alveolo-capillary membrane or by reduction in pulmonary capillary flow. Diffusion defects have been demonstrated, however, only in postthoracotomy patients where other aetiologies obtain (17). There is, in fact, circumstantial evidence to suggest that pulmonary capillary flow may be augmented at certain phases of I.P.P.

Defective diffusion of carbon dioxide is extremely rare, the more slowly diffusing oxygen being affected first. Thus a diffusion defect rarely demands increased tidal volumes, but always requires a raised oxygen content in the inffating gas.

\section{Mechanics of Respiration}

In normal spontaneous respiration, the work of breathing $(18,19)$ is performed by a muscular effort which creates a negative intrapleural pressure, with a resulting pressure difference across the alveolar wall. When this difference is sufficient to overcome the various resistances present, the lungs expand and air is drawn into the alveoli. The volume and distribution of this air depend upon the amount of muscular effort, the efficiency with which it is applied and the resistance offered.

Respiratory resistance consists of elastic and non-elastic elements (10). The former is produced by the elastic tissue of the lung and the chest wall (lung and thorax compliance), while the latter is produced by the inelastic tissues of the lungs and chest wall, the resistance to diaphragmatic movements, and the resistance to air flow. Through a normal respiratory cycle, air flow will vary from $0-40 \mathrm{~L} . / \mathrm{min}$. at rest. Expiration is passive, the elastic forces overcoming the resistance to air flow.

Any change in resistance will require a similar change in the work of breathing if ventilation is to remain constant. Many patients are unable to increase their work of breathing and consequently underventilate as resistance rises. The most obvious change in mechanics during I.P.P. is that the work of breathing is taken over, on inspiration, either partially or completely by the ventilator. Passive expiration is usually left to the patient, unless a negative phase is introduced into the respirator cycle. Machines designed for I.P.P. respiration should be capable of performing work equal to any resistance likely to be offered in clinical practice.

Elastic resistance (compliance) has been shown to vary under certain circumstances of interest in connection with respiratory insufficiency:

A direct relationship has been shown between height, lung volumes, and compliance, except in neonates in whom the compliance is about half that seer at all other ages (20), and in whom it may be still lower in the presence of hyaline membrane disease (21).

The lung-thorax compliance is low in anaesthetized patients (22) and in anaesthetized paralyzed patients $(23,24)$. In the latter, it has been shown that both total and component compliances are reduced and that this is not related 
to a rise in functional residual capacity. The reduction is related to a difference in distribution of the trans-alveolar pressure gradient by I.P.P. compared with normal spontaneous respiration (24).

A reduction in compliance has been shown in artificially ventilated poliomyelitics (23). In one series (25), it was observed that when spontaneous respiration was replaced by I.P.P. compliance and non-elastic resistance fell to approximately half the original value. Additionally, following I.P.P. during anaesthesia, using a respirator producing square wave respiration, a decrease in elastic recoil was noted (26).

Assuming the fall in compliance to be partly due to disuse, it has been suggested that it might be prevented in long-term respiratory insufficiency by daily inflation of the lungs to full volume. However, other reasons for the fall in compliance have been suggested $(22,23,24)$.

Many other causes of raised resistance arise, bronchospasm, atelectasis, accumulation of secretions, consolidation or pulmonary oedema, and pleural effusions being well recognized. Any small increase in dead space or reduction in compliance produced by I.P.P. itself is of small importance, given a machine capable of delivering adequate volumes of gas.

\section{Physiology of Breathlessness}

Breathlessness is an important, if sometimes a misleading, symptom whose applied physiology is obscure. In the context of respiratory paralysis, uncomplicated by pulmonary disorder, circumstances can be created in which breathlessness is not an indication of underventilation, defined in terms of blood gases (27). For example, if such a patient is chronically overventilated, the addition of carbon dioxide to the inspired air, without alteration of rate or tidal volume, will give rise to the complaint of breathlessness while the $\mathrm{pCO}_{2}$ is in the alkalotic range. Hence change, rather than absolute levell of arterial $\mathrm{pCO}_{2}$, is the stimulus causing change in the activity of the respiratory centre (28). Conversely, if the patient's tidal volume is reduced, he will complain of breathlessness before there is significant alteration of the blood gases. That is, mechanical stimuli alone will produce the symptom.

It is possible that breathlessness reflects a change in proprioceptive activity of muscles and that such a change may be induced by various means, mechanical and central. Central alteration of muscular activity via the muscle spindles is produced by change in the activity of the reticular formation of which the respiratory centre forms a part. Some such explanation is needed to account for the occasional anomaly in the occurrence and absence of breathlessness.

\section{Cardiovascular Effects}

An intermittent rise in intra-alveolar pressure, rather than a fall in intrapleural pressure, might be expected to reduce venous return and, consequently, cardiac output. However, it has been shown that provided ventilation is achieved by means of a respiratory pressure wave producing a low mean intrathoracic pressure, cardiac output does not fall and may even rise (29). The cause of this rise is not 


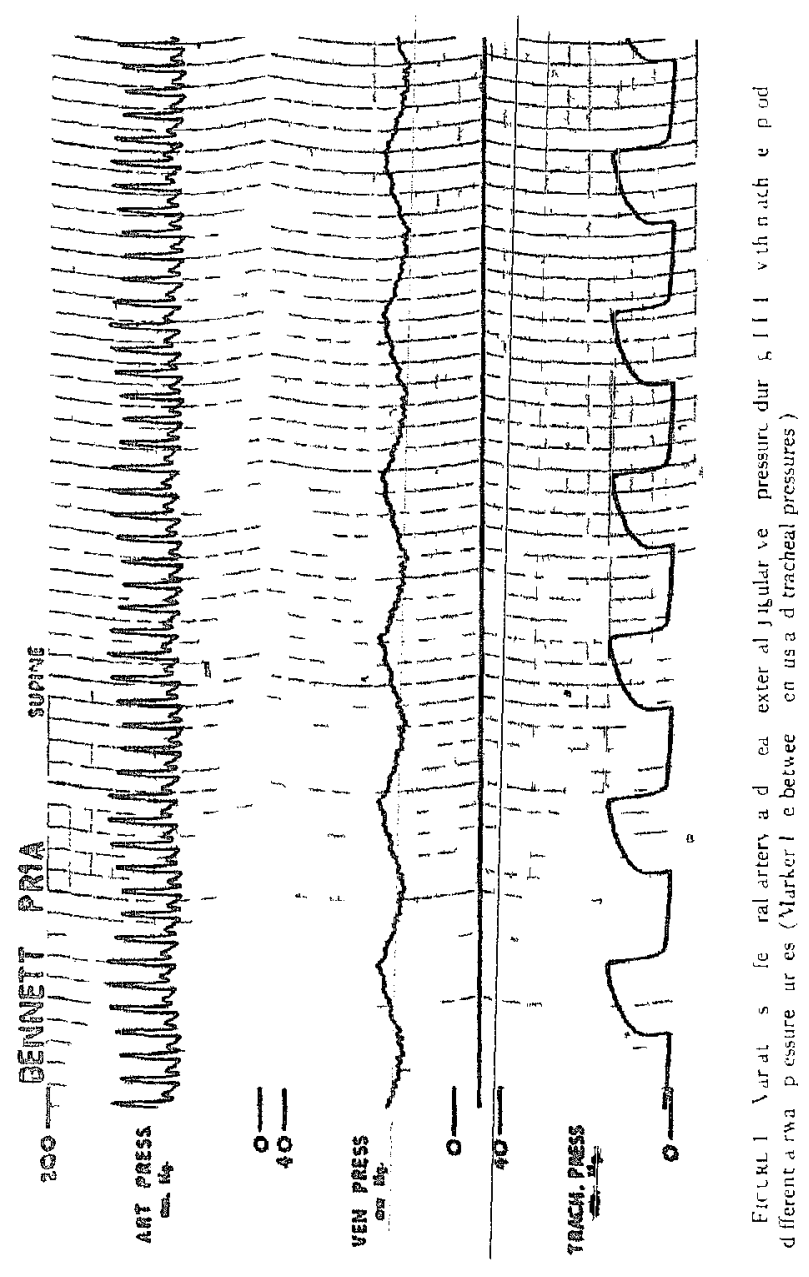




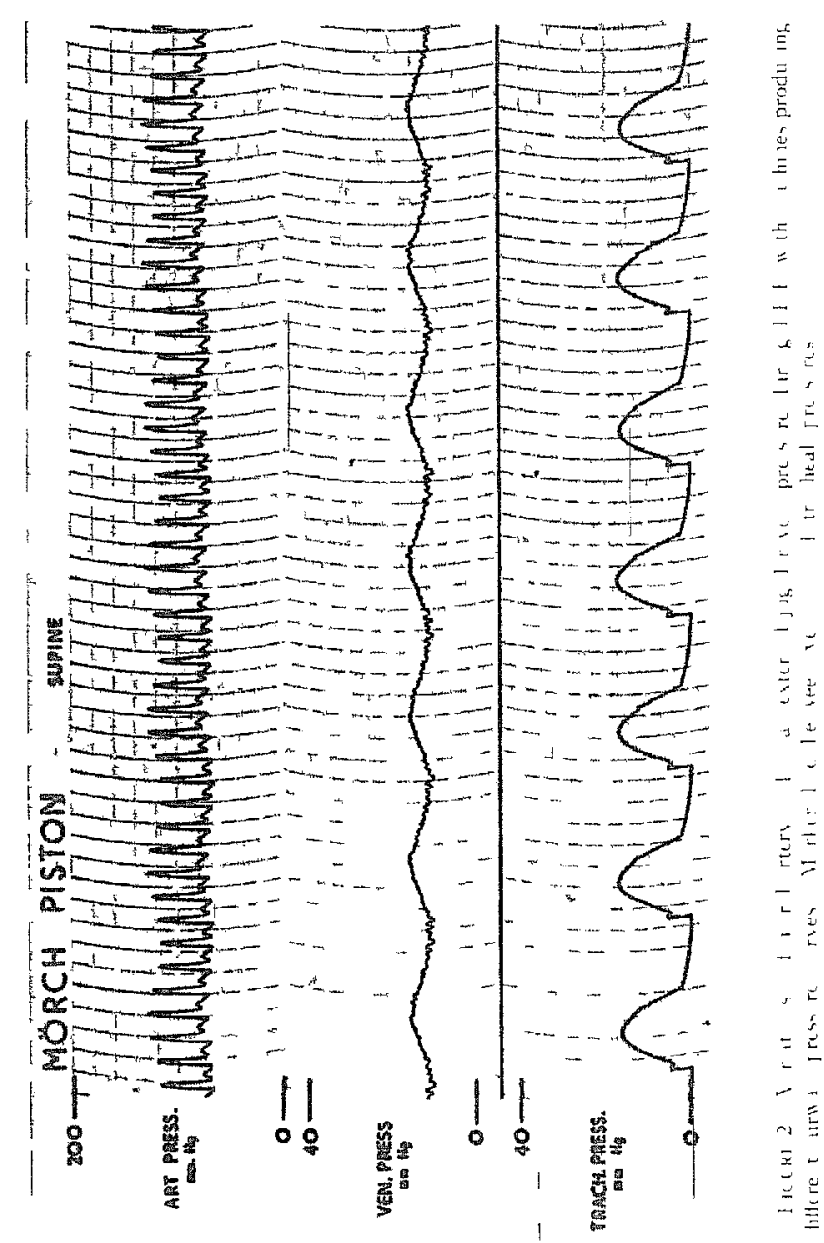


known, but it is of interest that modern respirators usually produce variations of systematic blood pressure within each respiratory cycle, the peak occurring at the point of maximum inflation pressure (Figs. 1 and 2 ). This may be due to improved left ventricular filling during a relatively short inflation phase. It has been suggested that this may be related to an increase in expanded lung, opening an unusual number of pulmonary capillaries, or to an increasing ejection of blood from the lungs through the course of each inflation. Thus, I.P.P. would convert the lungs into an auxiliary pump, filling during expiration and pushing blood into the lelt heart on inflation. Provided that the point of maximurn efficiency was not exceeded then, the heart action would improve and the stroke volume increase (Starling's Law). In the event of hypovolaemia, I.P.P lowers cardiac output, and this reduction may be reversed by introducing a negative phase to the respiratory cycle $(30)$.

There is thus the concept that each inflation reduces venous return but that this is offset by the ejection of blood from the lungs. If blood volume is low, the effect on venous return is greater and the intra-pulmonary blood volume less. Consequently, the reduction in venous return then has the predominant effect on cardiac output.

While the effects of I.P.P. on cardiac output predominate in variations in systemic blood pressure, the calibre of systemic vessels also varies with airway pressure (31-34) and with blood and tissue gas levels. The diameter of pulmonary vessels varies with the oxygen tension of blood perfusing chemoreceptors in the carotid and aortic areas and, possibly, with carbon dioxide tension $(35,36)$.

\section{-tcid-Base Balance}

The effects of I.P.P. on acid-base balance will depend primarily upon alveolar ventilation and secondarily upon renal function. In conditions of ventilatory instability 50 per cent of the change in body $\mathrm{CO}_{2}$ levels will occur within four minutes of changing ventilatory volumes (37).

In the treatment of patients previously in chronic respiratory acidosis it may take several days for the metabolic compensation to adjust. In such instances, reduction of the arterial $\mathrm{pCO}_{2}$ to normal will produce marked alkalosis. This has been noted in the presence of satisfactory renal function and in part may reflect the lag between the more rapid changes in labile forms of plasma carbon dioxide and the slower changes in tissue carbon dioxide stores.

Certain of the physiological problems encountered in the commoner causes of respiratory insufficiency will be discussed below, in association with their clinical management.

\section{INDICATIONS FOR ASSISTING VENTILATION}

The main indication for assisting ventilation is the presence of respiratory insufficiency due to a reversible condition. There are many such conditions other than those producing muscular paralysis and I.P.P. has been used in all. Other 
circumstances are, for example, to rest the respiratory muscles in a patient with advancing poliomyelitis, to prevent or relleve exhaustion from the work of breathing, and to prevent paradoxical movement of the chest wall. Finally, under some circumstances it is indicated as a means of delivering 100 per cent $\mathrm{O}_{2}$ for short periods.

The conditions in which underventilation may arise are exemplified in the following list:

(a) Conditions obstructing the airway, for example haematomata, inflammation of the upper airway, oedema, bulbar palsy, excessive secretions. This group is treated by relieving the obstruction but in the event of hypoxia, hypercarbia, and exhaustion, a period of respiratory assistance is often valuable.

(b) Neuromuscular disorders, for example, head injuries, overdosage of narcotics or hypnotics, brain stem lesions, cervical cord lesions, poliomyelitis, polyneuritis, myasthenia gravis, disorders of potassium metabolism, and so forth.

(c) Following the use of relaxant drugs, usually in the treatment of status epilepticus or tetanus.

(d) Pulmonary diseases, for example, emphysena, bronchiectasis, pneumonia, atelectasis, fibrosis, and left heart failure.

(e) Disorders of the thoracic walls, stove-in-chest, post-thoractomy, postlaparotomy, paralytic ileus, ankylosing spondylitis or kypho-scoliosis, extreme weakness due to debility.

Many of these conditions occur together. For example, a patient with ankylosing spondylitis may be precipitated into respiratory failure by pneumonia or by limitation of diaphragmatic movement and of coughing after laparotomy.

The clinical picture of underventilation is not uniform and varies with the condition which gives rise to it. Further, a perusal of the list will show how many other possible causes there may be of symptoms and signs such as disorder of consciousness, breathlessness, changes in pulse and blood pressure, of ten held to be characteristic of underventilation. This fallibility of clinical diagnosis is such that awareness of the possibility is the most important clinical factor and any suspicion should be promptly confirmed or rejected by measurement of the ventilation. Nonetheless, the clinical picture of acute underventilation demanding immediate treatment is characteristic, although uncommon. Extreme distress, sweating, cyanosis, violent respiratory efforts, tachycardia, hypertension proceed rapidly to coma, hypotension, gasping respiration, and death. The early stages have been called the Alarm Syndrome.

Similarly, chronic respiratory acidosis has characteristic clinical forms. The best known of these is the familiar aspect of the patient with advanced emphysema. Less well known is the presentation as a neurological syndrome (38) made up of headache, disorder of consciousness, papilloedema, involuntary movements, and a variable rigidity. These signs vary in prominence from case to case. A syndrome has also been described in which the patient appears partially curarized (39). This is probably non-specific and a similar picture has been described in association with marked metabolic acidosis (40).

It must be reemphasized that the pitfalls of diagnosis and of differential 
diagnosis are such that, in most cases, measurement of ventilatory volumes, with or without measurement of the blood gases, is essential.

\section{Tenilatory Measurements}

The clinical suspicion that underventilation is present may be confirmed by measuring ventilation itself.

Tidal volume. This may be measured in one of the following ways. (i) Spirometry-this is most applicable in the conscious unassisted patient. However, it is cumbersome and requires special measures to overcome problems of carbon dioxide retention and expiratory resistance. (ii) Collection of expired gases, via a non-return valve $(41)$ in a Douglas or plastic bag $(42,43)$. This also is somewhat cumbersome and still requires that the collected gas be measured by passing it through a spirometer or gas meter. (iii) Dry Gas Meter-this is a relatively accurate method of measuring expired gas volumes. The apparatus looks and functions in the same way as a domestic gas meter. By means of a non-return valve, expired gas is fed through the meter for one or more minutes, respirations counted, and a mean tidal volume calculated. (iv) Ventilation Meters-these are perhaps the most convenient means of measuring expired gas volumes. The gas passes directly through them, turning a system of vanes. Reasonable accuracy is attained at all except the lowest gas flows. The most recent of these, the Wright Anemometer (14) (Fig. 3), can be placed in continuity with the airway, measuring gases passing in one direction only, and offering minimal resistance. It is extremely small and portable, the face being the size of a large wrist watch. The main objection to this type of 'equipment has been the fragility of the last named and the possibility of moisture from humidifiers altering the response of the vane and therefore the accuracy. More rugged but less easily manipulated are the Draeger and Monaghan meters ( 41 ).

By means of equipment of this type, the patient's tidal volume may be followed. Expired volumes are chosen as these are the more reliable when using I.P.P. Under such circumstances, some of the inflation volume may leak out between being measured and passing into the bronchi, whereas all the measured expired volume nust come from the tracheo-bronchial tree. Comparison with a ventilation nomogram and consideration of the possibility of an enlarged physiological dead space will determine the likely adequacy of ventilatory exchange.

Having confirmed one's clinical impression by measuring ventilatory volume, any remaining doubts may be cleared by measuring arterial $\mathrm{pH}$ and $\mathrm{CO}_{2}$ levels, which provide the only absolute guide to respiratory status (45). It should be stressed that $\mathrm{CO}_{2}$ levels alone are not always sufficient owing to the not infrequent coincident metabolic changes in seriously ill patients.

Blood gas measurement. Arterial $\mathrm{pCO}_{2}$ may be measured as follows:

(1) Directly $(46,47)$. This is technically difficult and not available in the average hospital laboratory.

(2) Derived from:

(i) ph and $\mathrm{CO}_{2}$ content of arterial blood (48);

(ii) $\mathrm{pH}$ of arterial blood and $\mathrm{pH}$ of the same sample after equilibration with a gas of known $\mathrm{pCO}_{2}\left(\frac{19}{19}\right)$; 


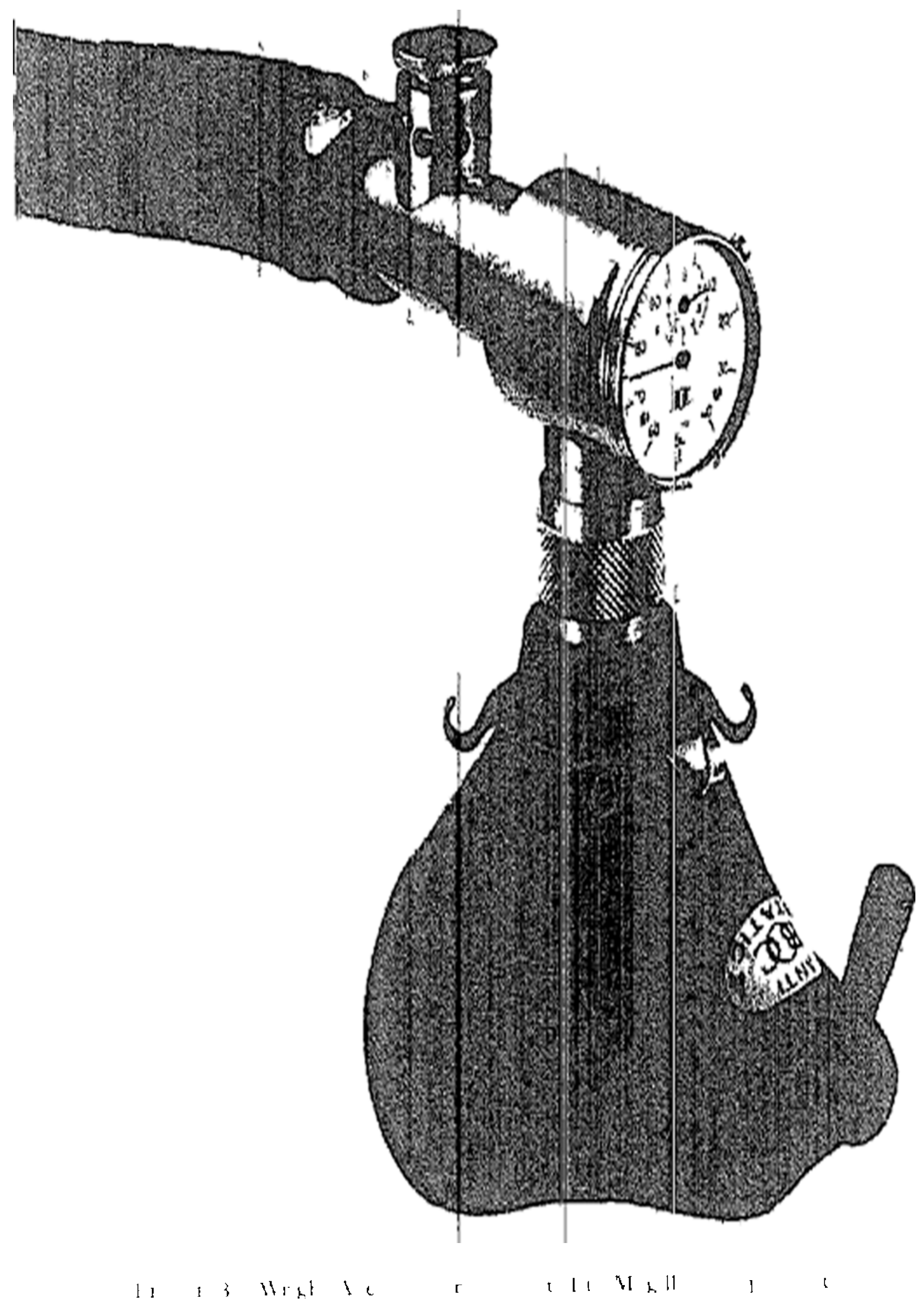


(iii) Alveolar gas sample, by single prolonged expiration or by modifications of the Plesch method (50-53), the gas being analysed by Haldane (47) or Scholander (5t) apparatus, infra-red analyser $(55-58)$ or one of several other more simple but, in most instances, less accurate methods (59-62). One of the latest of these methods has the merit of simplicity and relative accuracy (52) but all require an additional $\mathrm{pH}$ value for a complete picture.

(3) Assumed from:

(1) $\mathrm{CO}_{2}$ combining power. This is essentially a measure of slowly changing metabolic factors. It is relatively valueless in acute respliratory problems and in the presence of combined metabolic and respiratory disorder $(45)$. It may indicate the trend in chronic respiratory states. To derive maximum benefit from this estimation, within its limits, it should be considered in association with a $\mathrm{pH}$ value;

(ii) Arterialized venous samples $(63,64)$. When the forearm and hand are warmed and venous blood is taken from the dorsum of the hand, without tourniquet, good correlation with arterial values is obtained in normothermic normovoluemic patients;

(iii) End-tidal samples $(6 \overline{5}-6 \overline{7})$. Continuous readings may be made of the carbon dioxide levels in end-tidal air, using infra-red or photochemical principles. This value will follow that of the alveolar air if the tidal volume remains constant, but the absolute level will be of no special significance when measured alone.

Thus, arterial carbon dioxide levels may be determined by one of a number of procedures, of which the Astrup method has been found very satisfactory (method 2 (ii) above). A specialized virtue of this technique lies in the possibility of its use in patients recently given a volatile andesthetic agent and the simultaneous availability of a pH value.

Oxygen administration. One must consider under what circumstances oxygen should be added to the inspired air. If a patient has normal lungs, this will not be necessary. However, any suspicion of a distribution or diffusion defect will indicate the addition of oxygen. I.P.P. creates one of the few circumstances in which 100 per cent oxygen may be delivered to the lungs for a prolonged period and the harmful effects of this should be remembered (68).

When adding oxygen to an apparatus delivering air, it may be difficult to assess the effectiveness of this addition. Improvement in oxygenation may be shown by a slowing of the heart rate but more reliable information may be obtained by (i) analysis of inspired or expired air by oxygen analyzer (69), (ii) oximetry (70-72), or (iii) intermittent arterial sampling and manometric analysis (73). In cases of marked desaturation, one may increase the flow of oxygen until no further improvement occurs in (ii) or (iii). In this way, maximum efficacy is achieved without the possibility of oxygen toxicity.

\section{Clinical Application of Measuremeris}

The way in which the measurements of respiratory volumes and blood gases are used in clinical practice is as follows:

(a) The initial decision to ventllate. In all cases not in extremis, ventilation is measured. The conscious patient is asked to breathe through a mouthpiece into 
one of the measuring devices described above, after the application of a nose-clip. In the unconscious subject; nose-clip and large-flanged mouthpiece, facepiece, or cuffed endotracheal tube may be used. Values obtained are compared with a ventilation nomogram, and the first of a series of values is thus available. The decision to ventilate may be made on the basis of unequivocal underventilation shown on the first reading, or as a result of gradual deterioration as indicated by serial reading.

Unless ventilation is very obviously adequate, the arterial $\mathrm{pCO}_{2}$ is then determined. Underventilation, as shown by tidal volume and arterial $\mathrm{pCO}_{2}$, is taken as an absolute indication for assisted respiration except in two circumstances: (i) chronic respiratory acidosis with no evidence of recent deterioration and without trial of less drastic measures; (ii) minor degrees of acute respiratory acidosis in a rapidly improving situation, for example, recovery from deep anaesthesia.

(b) Monitoring of efficiency of assisted respiration. During 1.P.P. the following measurements are made, in addition to routine clinical observations: (i) tidal volume, (ii) inflation pressure, (iii) arterial $\mathrm{pCO}_{2}$. The volume necessary to achieve a normal arterial $\mathrm{pCO}_{2}$ is noted at the outset and the pressure necessary to achieve this volume is observed. Frequent measurements of ventilation will be needed in the acute stages.

Further arterial $\mathrm{pCO}_{2}$ values will be obtained only when doubt exists as to the respiratory status, for example, in managing patients with gross pulmonary disease or as a very occasional check in patients needing prolonged treatment.

\section{Management of Airway and Ventilation}

The equipment necessary for the management of respiratory insufficiency by I.P.P. may be grouped as follows: airway and suction equipment; non-return valve; humidifier; ventilator.

AIRWAY. A small group of patients can be managed satisfactorily by means of a face-mask or nose-clip and mouthpiece, using no artificial airway of any sort. These are conscious patients with chronic respiratory disease and considerable insight. With a little training, they can use I.P.P. in this way to deliver bronchodilators, vasoconstrictors, and wetting agents $(74,75)$. Improved bronchiolar calibre and elimination of secretions may then improve ventilation. Such therapy has usually proved impracticable in the treatment of severe respiratory insuffciency and lends itself more to the less severely affected group of patients with chronic respiratory disease.

It is obligatory to create an airway and start ventilation as soon as underventilation is recognized. Even brief delay may result in cardiac arrest. The usual practice is to pass a cuffed orotracheal tube, a tracheostomy being performed subsequently if required. Tracheostomy is considered to be indicated when it is evident that the problem cannot be corrected within an arbitrary 24-48 hours. When early recovery is probable (e.g., barbiturate poisoning), tracheostony is postponed. In all other cases, it is best delayed until resuscitation has been carried out, when the patient will be adequately ventilated, hydrated, and, if necessary, transfused and digitalized. 
In all cases not in extremis, intubation is carried out under a minimal dose of sodium thiopentone and succinylcholine, using careful topical anaesthesia. If thiopentone is contra-indicated, the technique depends on the patient's level of consciousness. Thus, if amnesia is probable, muscle relaxant and topical anaesthesia are used. If the patient is more conscious, topical anaesthesia is used alone, in which case transtracheal instillation is preferred.

The need for great gentleness and maximal relaxation is emphasized by the occurrence of post-intubation granulomata of the vocal cords in two cases in which technical difficulty arose. Relaxants were not used and in one case the tube was only in place eight hours.

Once the airway is secure, the patient is sedated until he becomes accustomed to his new circumstances. In many instances he will become very much less agitated once adequate ventilation is established. However, in rare instances where sedation does not settle the patient and adequate ventilation cannot be achieved, muscle relaxants may be required as a temporary measure.

Tracheostomy. The virtues of tracheostomy in the treatment of respiratory insufficiency are as follow's:

(i) Access for I.P.P.

(ii) Access for suction.

(iii) Protection from aspiration of pharyngeal secretions by using a cuffed tracheostomy tube.

(iv) Freedom from equipment about the mouth and nose, permitting the use of duodenal tubes, normal cating and drinking, and so on.

(v) Reduction of dead space. The latter factor is offset, when using I.P.P., by the added dead space of the apparatus and by the increase in physiological dead space produced by I.P.P. itself (16).

I.P.P. is not possible in conjunction with the usual types of tracheostomy tube, without an adaptor which fits into their lumen. This reduces the diameter of an already narrow airway.

Special equipment is usually preferred and a variety of tubes has been described. They should (a) be of adequate diameter (from 9-12 mm. internal diameter for adults), to minimize resistance to gas flow and to decrease the likelihood of obstruction by secretions, and $(b)$ have adequate connections for attachment to I.P.P. equipment. The latter should not narrow the lumen and should be moveable through $360^{\circ}$ (e.g., metal to metal slip-joint), in order that the I.P.P. equipment can remain stationary when the patient is moved.

Two main types of tracheostomy tube are in use: those with and without inflatable cuffs. The latter $(76,77)$ are less versatile, do not permit measurement of ventilation, and do not prevent aspiration of secretions from the pharynx. However, they have been advocated in the treatment of stove-in-chest by induced respiratory alkalosis (78). They are also of value in the management of tracheal ulceration secondary to over-inflation of cuffed tubes.

Cuffed tracheostomy tubes may be improvised by stretching a latex cuff over a large tracheostomy of laryngectomy tube but are also commercially available with an incorporated cuff. The former are usually made of metal or plastic and have the advantage of an inner cannula. However, the metal tubes usually leak 


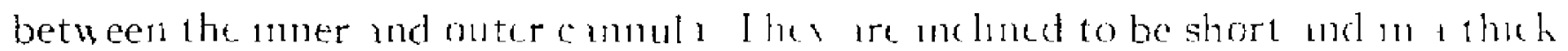

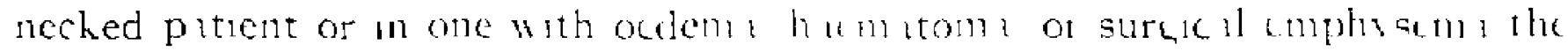

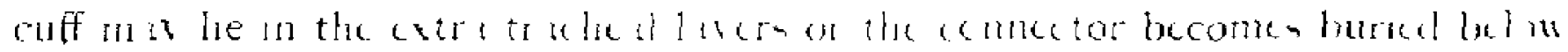
ating lev

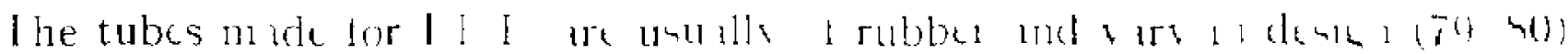

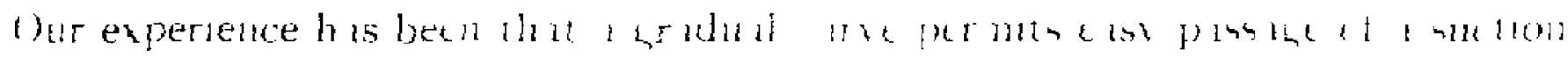

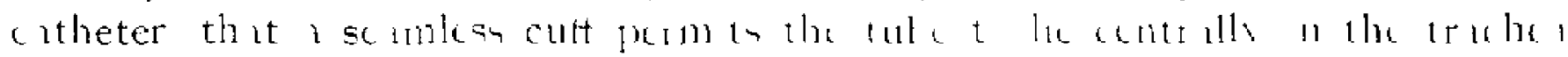

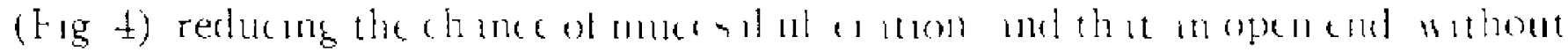

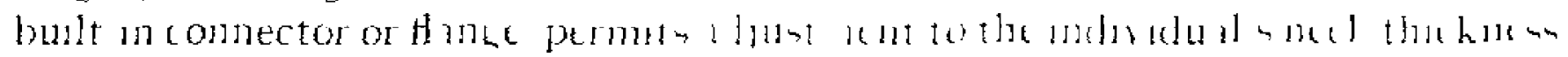

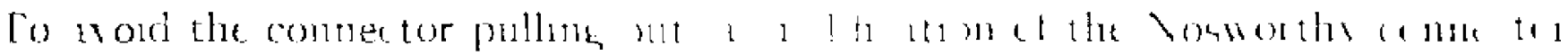

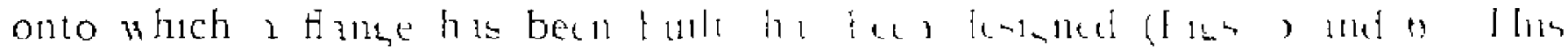
4 dilizes the whole tube

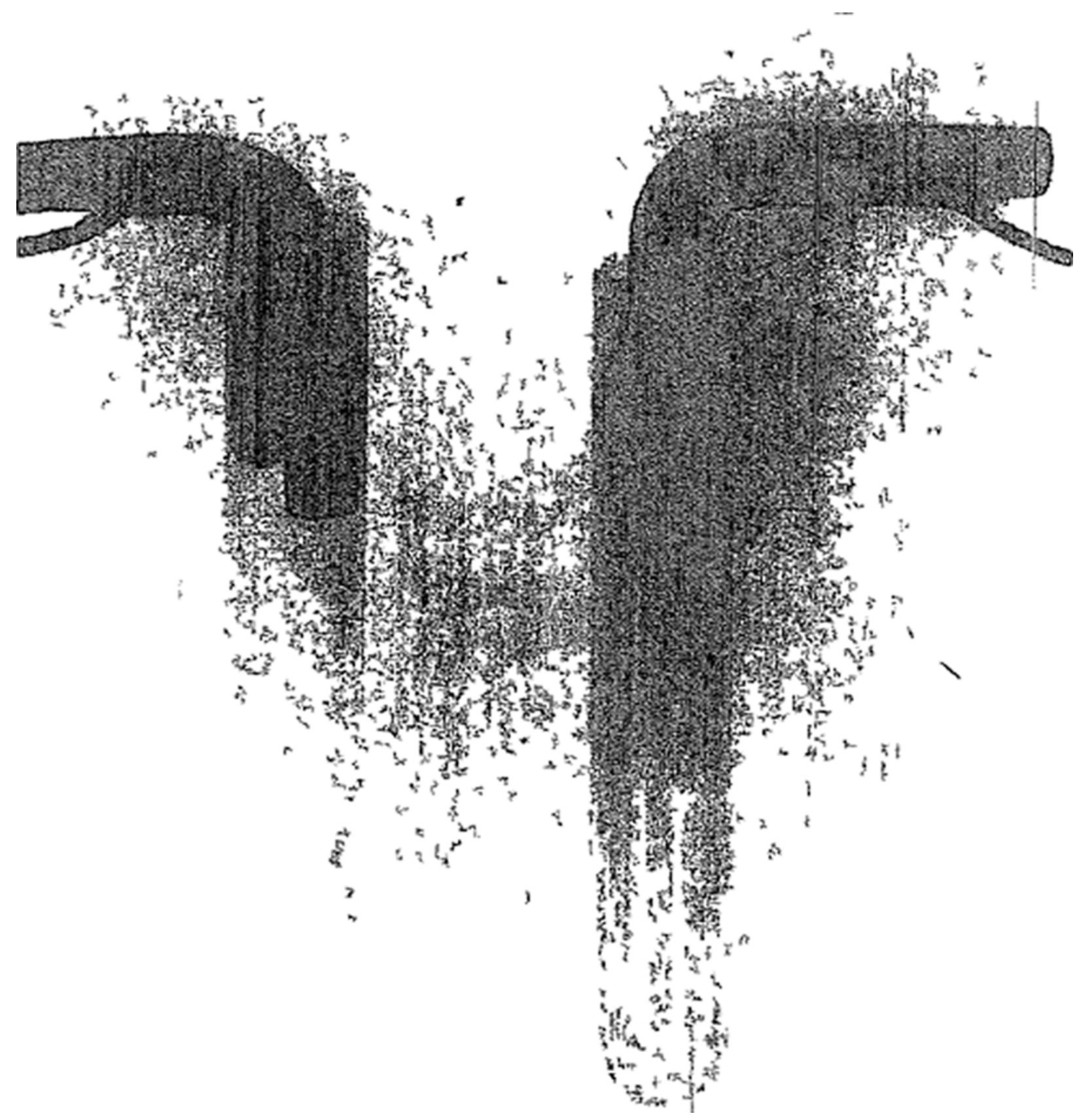

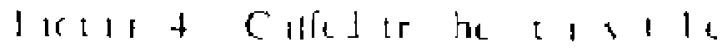

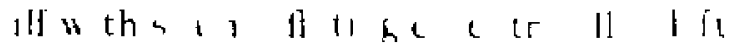

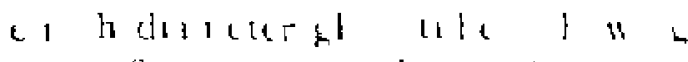

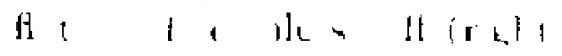



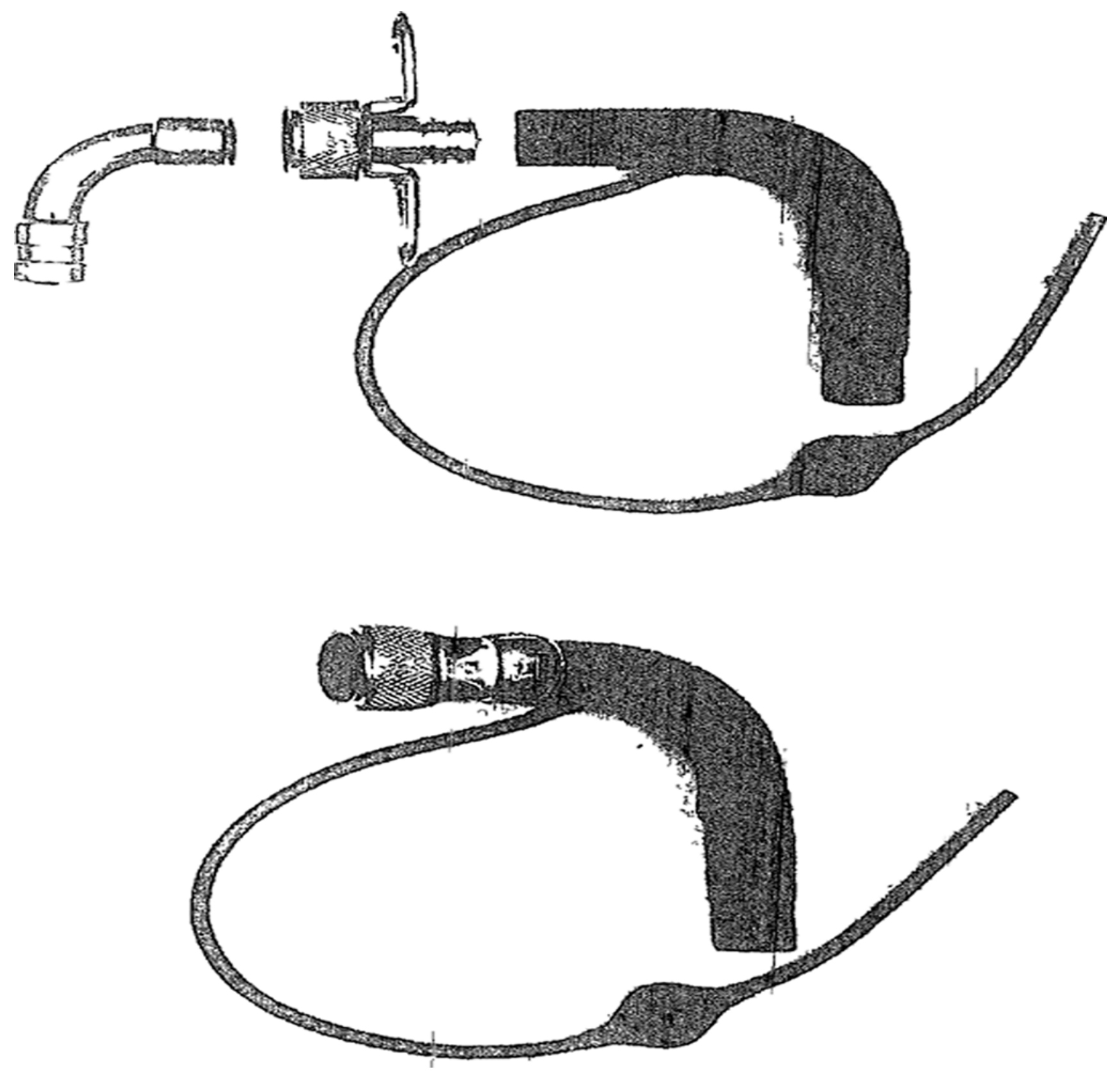

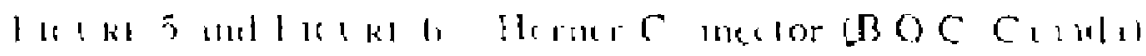


To permit the cuff to lie within the trachea, the intratracheal portion is relatively long. In consequence, the tracheostomy must be high and the second ring or space should be divided. The cricoid should be protected by an intact first tracheal ring. It is important that the end of the tracheostomy or endotracheal tube should be high enough to allow suction catheters to pass easily into the left main bronchus. Adequate air entry bilaterally does not indicate that the tube is high enough, only that it is not in the right main bronchus. A further reason for high tracheotomy is that the lower the opening, the nearer the tube is to the great vessels of the neck and the greater is the danger of massive secondary haemorrhage. This is more probable if the origin of the vessels is anornalous (81).

A circular window is cut from the trachea, following division of the thyroid isthmus. Both these manceuvres are performed routinely and have been found valuable not only at the initial insertion but in case early changing of the tube should be necessary. In the latter event, there is less likelihood of the tracheostomy being closed, as though by a series of shutters, when the tube is withdrawn.

As stated above, tracheostomy is performed semi-electively, assisted ventilation being carried out throughout the operation. The endotracheal tube is withdrawn completely from the glottis only when the tracheostomy tube is securely in place. Atropine is given as premedication in all instances and this is accompanied by a narcotic uniess contraindicated. Respiratory depression from the narcotic is not usually a serious consideration in patients receiving artificial ventilation.

In this series, general anaesthesia was used for almost all tracheostomies. This varied from 50 per cent nitrous oxide with oxygen and muscle relaxant to sodium thiopentone: nitrous oxide: halothane with or without relaxant, according to the patient's general condition.

Changing Tracheostomy Tubes. It has been found advisable to change rubber tubes more frequently than metal. If tracheostomy is followed by marked oozing of blood, a change after 24-48 hrs. may be required. More usually, however, a weekly change suffices. Until the tracheostomy is firmly established, difficulty may arise during this procedure and two people should be present. One intubates the trachea through the glottis, before the tracheostomy tube is removed. In this way, ventilation is under control throughout.

Complications of Tracheostomy. Those most commonly seen are infection and mucosal ulceration. The former is treated in the normal way and did not prove worrying in this series. The latter may give rise to considerable anxiety and is most likely in patients exposed to the effects of hypotension. Bleeding from tracheal ulceration must be distinguished from that due to other causes, for example, tracheitis sicca. Treatment seems best carried out by use of an uncuffed tube and the Mörch technique. Suction may aggravate the situation and, if tracheitis sicca is suspected, the use of a machine producing sudden powerful expiratory movements has been recommended (82).

Cardiovascular collapse following tracheostomy has been described and various causes suggested (83-85). Among these, sudden reversal of hypercarbia with possible accompanying electrolyte disturbances is commonly accused. Sudden collapse during tracheostomy may relate to vagal overactivity from hypoxia and mechanical stimulus especially when atropine has been omitted. 
In the present series, no post-tracheostomy deaths were observed, although hypotension requiring vasopressors for some hours has been seen. This usually followed tracheostomy in patients who had suffered severe hypoxia and it is thought that a resulting reduction in myocardial efficiency was responsible. Electrocardiographic evidence of myocardial ischaemia was observed in several instances.

Bronchoscopy. This has been found to be of very occasional value and may be dangerous. Bronchoscopic equipment should be constantly available and has been found life-saving in two situations: (i) Haemorrhage within the bronchial tree, the combination of blood and secretion forming crusts not removable by suction catheter. (ii) Marked crusting in association with staphylococcal pneumonia. Again, two persons should be present and only very limited periods without ventilatory assistance should be permitted. If the larynx is not of immediate interest, the bronchoscope may be passed through the tracheostomy.

NON-RETURN VALVES (41). Some form of non-rebreathing system is preferable to one providing carbon dioxide absorption, for a number of reasons:

(i) The circuit becomes simpler.

(ii) Soda-lime does not have to be changed.

(iii) Expired gas can be collected and measured.

(iv) Contamination of the machine is less likely.

(v) Expiratory resistance may be lowered.

In practice, non-return valves have certain limitations:

(i) They tend to "leak," so that a portion of the expired gas is rebreathed. This is of little consequence, except in volume measurements. Using such a valve, for example, Flutter-type valve, Reuben Valve, Mörch Valve (78), a meter must be placed between the valve and the patient. In this regard, the Wright Anemiometer is particularly useful.

(ii) They render insertion of a negative phase more difficult, although such a phase will increase the efficiency of flutter valves by causing early closure.

(iii) Some of those which close efficiently on expiration, offer a small but significant expiratory resistance at normal flow rates, for example, the Etsen modification of the Fink valve permits collection of expired gases and closes promptly but has an expiratory resistance of $3-5 \mathrm{~cm} . \mathrm{H}_{2} \mathrm{O}$ at normal flows. However, such a valve may be inserted in a circuit temporarily for purposes of measurement.

Many machines are equipped with non-return systems and mostly belong to the group of intermittently opening reducing valves (see below). Some have a housing around the expiratory valve from which expired gases may be collected.

When the machine is not equipped with a valve, the Mörch non-return valve has been found to be efficient, as has the Beaver flutter valve. These are placed as near to the patient as possible, to minimize dead space. They must be changed at intervals and therefore more than one must be available for each patient. The former is changed and cleaned daily, the latter every two hours. This is necessary because moisture collects on the rubber diaphragm and hampers its free movement.

HUMIDIFIERS. Patients must be adequately hydrated and the respiratory gases must be humidified. Lack of attention to this causes a high incidence of pulmonary 
complications. Certain machines are equipped with humidifiers, although the efficiency of these varies. While a high relative humidity is desirable in all patients, actual droplet administration is frequently of value. This is the case in all patients with copious secretions, or in those requiring intrabronchial medication. The droplet size should be $0.5-10 \mu$ (86), which is provided by relatively few pieces of equipment. Larger droplets are inefficient in liquefying sputum and may cause respiratory embarrassment, while smaller droplets are absorbed too quickly. The optimum size is probably $3-5 \mu$.

Where a machine is to be used which does not have a humidifier, one must be placed in the circuit. One may either deliver the inflation volume over hot water (87) or put a T-piece into the circuit near the patient and deliver droplets from a nebulizer by this means. Alternatively water (not saline) may be delivered from an infusion set through a needle inserted in the inflation tubing. The possibility of tracheostomy infection from humidifiers should be remembered. Meticulous cleanliness is essential.

VENTILATORS. These have been discussed at length in recent publications $(41,88)$ and vary greatly in design and efficiency. They may be discussed under a variety of headings.

(a) Motive force. This is either an electrical motor or compressed gas, each having its advantages and disadvantages. The former is relatively reliable, expensive initially and requires to be of a special approved type. The latter is more common, less expensive, and very variable in reliability. Both forms of motive force are subject to failure and each patient should have an alternative method of hand ventilation available at all times. In this regard, the Ambu type resuscitator (89) has proved most useful.

(b) Circuits. Essentially, these fall into three groups. (i) Pistons or bellows which draw in room air on opening, then, by a series of valves, deliver this to the patient. Both electrical-and gas-operated machines fall into this group. (ii) Motor blowers: essentially, these are intermittently functioning reversed vacuum cleaners. (iii) Intermittently opening reducing valves. These are all compressedgas-operated machines, functioning by exposing the patient's airway intermittently to a source of compressed air or oxygen. The pressure at which this exposure is made and the rate at which the gas flows is controlled by the machine. These are usually patient triggered but may also be equipped with an automatic sett ng.

Also in this group is the pneophore valve which, by means of a diaphragm mechanism, controls the flow of gases. This latter type of equipment is of limited value for the prolonged treatment of respiratory insufficiency.

(c) Principles of operation. Machines must have one of two limiting factors to inflation. This is either a preset pressure or volume. Consequently, machines are all either pressure constant-volume variable or volume constant-pressure variable $(90)$. In the first instance, tidal volume will fluctuate inversely with changes in total resistance. In the second, the tidal volume will remain constant while the pressure at which it is delivered varies directly with the resistance. In each instance, this variable factor is limited by the machine's capabilities. For most 
purposes, a versatile machine should be capable of delivering over $1000 \mathrm{ml}$. per stroke and pressures of $50-60 \mathrm{~cm} . \mathrm{H}_{2} \mathrm{O}$.

Certain features are essential on all volume-constant machines. (i) They should have a manometer in the circuit, for use as a resistance meter. An increase in pressure suggests the possibility of the need for bronchial aspiration, correction of bronchospasm or left heart failure, or the need for more muscle relaxant in conditions such as tetanus. (ii) They should also possess a safety valve so that a lung will not be ruptured, if the resistance rises precipitously, the machine inexorably delivering its preset volume. The Mörch respirator (78) has been found to be a very reliable, if not versatile, machine. Being intended for use with an uncuffed tube, it possesses neither safety valve nor manometer. The humidifier has been found inefficient and, in consequence, the following modification has been introduced and found to be a great improvement. The humidifier cylinder was removed and, in its place, a one-inch diameter threaded tube was inserted. To this was attached the delivery tube to a separate humidifier. An anaeroid manometer and a blow-off valve (loaded at $50 \mathrm{~cm} . \mathrm{H}_{2} \mathrm{O}$ ) were tapped into the top of the one inch tubing.

(d) Respiratory wave form. Opinions differ as to the optimum wave form. Certain machines apply I.P.P. to the upper airway in a preset wave form while, in others, the duration of each phase and the shape of the pressure curve produced may be adjusted. The sinusoidal curve has been strongly advocated as that likely to effect curdiac output least. However, a square wave is held by many to give the greatest inflation in the shortest time. The square wave is produced by machines delivering high gas flows from the start (e.g. 100-200 L.'min.). Maximum pressure is reached rapidly in the upper airway (giving a vertical up-stroke to the inflation curve). Ventilation is then largely dependent upon the duration of application of this pressure (giving a horizontal component to the curve). The potential disadvantage of such wave form might be that in patients with low compliance ventilation would only be achieved at the expense of venous return.

If a severe distribution defect necessitates slow inflation or spme expiratory retard is utilized to prevent trapping, the vertical components of the wave form will be impracticable and a sinusoidal curve more desirable. Again, venous return will be impeded.

Inflation. During this phase, tidal volume will be determined. Air should be delivered at a flow of at least $40-60 \mathrm{~L}$. per min., and it should be possible to achieve this fairly rapidly. The intermittently opening reducing valve type of machine usually delivers gas at over $100 \mathrm{~L}$. per min. and at least one is capable of flows up to $200 \mathrm{~L}$. per min.

This phase is adjustable on many machines and should be as fast as is compatible with adequate ventilation, distribution and comfort. Patients with pain in the chest object to machines reaching maximum inflation pressures extremelg. ralpidly:

Expiration and Pause. These two phases together should be at least as long as inspiration and preferably longer to permit adequate venous return (29). Expiration itself should be as rapid as possible except in patients with air trapping. 
In the latter, a small resistance in the first part of expiration may diminish trapping. Again, phase adjustability and an adjustable expiratory retard may be of value.

Negative Phase. This has been shown to be of value in hypovolaemia (30) and in patients with low lung volumes (91). The danger of accentuating trapping in emphysema has been suggested (92) and no improvement in ventilation has been demonstrated using a negative phase in a small series of such patients (25). It may be most valuable when inserted at the end of the expiratory phase (93).

(e) Patient-triggering mechanism. Certain machines possess a mechanism whereby each respiratory cycle is initiated by the patient creating a small negative pressure in the circuit. This may be fixed to work at, say, $-2 \mathrm{~cm} . \mathrm{H}_{2} \mathrm{O}$ or may be variable. Most machines with such a device can also be set to work automatically. Frequently, the automatic control may be set at a slower rate than that of the patient so that, should he fail to trip the machine, it will then cut in on its own. While this mechanism is not essential, it has been used very frequently in the present series and has been most helpful. The patient triggering mechanism is contraindicated in the treatment of stove-in-chest, until the weaning phase is reàctred. Clearly, it will be inappropriate in the presence of apnoea.

(f) Machines of use in both operating room and respiratory insufficiency. Certain machines are designed in such a way that they may be used either in the operating room or in the treatment of respiratory insufficiency. Although such versatility usually leads to compromise, the concept is most appealing to the smaller hospital. The essential differences between the two types of ventilator are these:

(1) A machine for use in anaesthesia must have a circuit, separate from the motive force, into which one may introduce anaesthetic gases. Several machines, designed for anaesthesia and possessing such a circuit, can be modified for I.P.P. therapy by opening an air intake valve. Thus, as the bellows expands, instead of anaesthetic agents filling it, air is drawn in. As the bellows empties, the air valve closes and the air is delivered to the patient. Under such circumstances, the machine must obviously be used with a humidifier and non-return valve. When used for anaesthesia, these are removed and the machine substituted for the rebreathing bag of an ordinary anaesthetic circuit, with its own circle system, to and fro absorption, or non-return valve.

Clearly, such interchangeability is not possible with the intermittently opening reducing valve type of respirator. However, they may be adapted for use in anaesthesia (as may the bellows or piston type not designed for this purpose) by placing the rebreathing bag of the anaesthetic circuit in an airtight container and applying I.P.P. to the space between bag and container (94). Such a machine has now been made available commercially.

'(2) Machines for use in operating rooms must, be explosion-proof, rendering those which are gas-operated most frequently acceptable.

(3) Máchines used in operating rooms may be relatively complex, but satisfactory under the continual observation of a physician. Such a machine may be difficult for the inexperienced nurse to understand. 
(1) Machines for respiratory insufficiency require a humidifier and non-return valve. (See above.)

(5) Machines used in treating respiratory insufficiency may be in use for weeks on end; after anything more than the few hours customary for anaesthesia, minor imperfections of pressure wave form, expiratory resistance, and long-term reliability become of increasing importance.

(g) Alternative methods of venilation. Emergency equipment, with which to ventilate any patient whose ventilator ceases to function satisfactorily for any reason, must always be available. Attendants should all know how to use this and, in cases of emergency, must do so until help is obtained.

(h) I.P.P. in children. As mentioned above, a given volume of air will be delivered at a specific pressure regardless of the age of the patient, the only exception being neonates. Thus I.P.P. equipment for children will require only slightly lower pressure ranges than those of adults. However, considerations of volume and rate will be very much more critical. Bearing in mind that a 7 -lb. infant may have a tidal volume of $20 \mathrm{cc}$., it is obvious that dead space must be minimal. Similarly, an infant's respiratory rate may require a ventilator to function as fast as 40 per min.

\section{Clinical Management}

The sections that follow will be concerned with the clinical application of the above principles, without any discussion of first aid:

Patients requiring assisted respiration present in two ways: the first is the patient who needs respiratory assistance at once; the second is the patient whose ventilation fails gradually while he is under observation.

The first group needs emergency treatment. An airway is established and ventilation started as previously described. In an acute emergency of this type, measures to secure these ends take precedence over all other considerations. When they are secured, a complete history can be obtained, physical examination carried out, and other emeryencies dealt with.

History taking and examination will have been done, of course, in the case of the patient with respiratory failure of gradual onset, but the following investigations are important: chest $\mathrm{X}$-ray, $\mathrm{Hgb}, \mathrm{WBC}$ and differential, complete urine examination, serum electrolytes and NPN, ECG examination, culture of the bronchial secretions, and measurement of ventilation. If facilities exist, the arterial $\mathrm{pH}, \mathrm{pCO}_{2}$, and $\mathrm{CO}_{2}$ content should be determined before the institution of artificial respiration and an hour or so after it has begun.

In general, the use of I.P.P. does not alter the management of most conditions in which it may be needed but a few points merit special emphasis. Successful treatment depends upon attention to detail and this must be impressed upon all who deal with these patients. This is the only way in which minor deviations from normal can be previnted from turning into major catastrophes and this responsibility falls in the first place upon the nurses.

Nursing care. The successful use of assisted ventilation depends upon the skill 
of the nurses, who should therefore be specialists. In practice, several months' experience are needed to acquire the necessary skill and confidence. The nursing problems are those associated with the nursing of very sick patients, the use and the understanding of the specialized equipment, and the recognition and management of a developing emergency.

Apart from general nursing care, the following are the routines in use in the Respiratory Unit at the Toronto General Hospital in acute cases: half-hourly observation of heart rate, blood pressure, respiratory rate, and airway pressure; half-hourly tracheal toilet-or more frequently if necessary-and note taken of quantity, consistency, and colour of the aspirate. The humidifier must always be kept full. In some patients, half-hourly or hourly record of the ventilation is made. Every two hours, the patient is turned and the cuff on the tracheostomy tube is deflated for two minutes and then reinflated; there is no good evidence that this is necessary to prevent ischaemic ulceration of the trachea but it is done in the hope that it will. The patient's temperature is recorded every four hours and the fluid balance every eight.

The large number and variety of nursing problems that arise in these patients will become apparent in the sections that follow. The outline given above refers to the acute case. As the patient improves, the various observations may be made less often and the frequency of suctioning is adjusted to the amount of secretions present.

The care of the chest. The problems in the chest are the prevention of atelectasis and of infection. These arise because the natural barriers to and humidification of the respiratory tract are bypassed and because effective coughing is abolished. The presence; of a foreign body, the tracheostomy tube, in the trachea promotes the formation of secretions and, particularly in asthmatics, tends initially to aggravate spasm of the broinchi. In a few patients, the bronchial and tracheal mucosa is destroyed by infection.

Bronchial secretions are removed by catheter suction. They are brought within reach of the catheter by physiotherapy to the chest. The value of chest phrsiotherapy, that is of percussion and squeezing of the chest wall, has been emphasized by many writers $(95,96)$. All patients in the Toronto General Hospital Respiratory Unit, except those with stove-in-chest or in shock, are given physiotherapy twice daily by members of the department of Physical Medicine. It is useful for the nurses to have some knowledge of chest physiotherapy.

Suctioning is done with sterile coudé rubber catheters, size 16 or 18 , which are used once and then resterilized. These catheters are of soft rubber, hollow to the end. The hole is about $1 \mathrm{~cm}$. from the end. Straight catheters enter the right bronchial tree on the vast majority of occasions (97).

The catheter is connected to the suction machine via a y-piece, one limb of which is open to room air. The machine is turned on and the catheter inserted with the tip pointing to right or left, depending upon which main bronchus is to be aspirated. It is gently insinuated as far as it will go. A finger is then placed over the limb of the " $y$ " and the catheter gently withdrawn with a slight twisting movement. The procedure is repeated until all reachable secretion has been aspirated from both sides. While this is done, the patient must be disconnected 
from the ventilator. To prevent hypoxia, it is a safe rule for the inexperienced nurse to hold her breath from the moment that she disconnects the ventilator and then reconnect it when she has to take a breath herself.

To maintain secretions fluid enough to be aspirated, the inspired gases must be properly humidified, but the most perfect humidification of the inspired air will be useless if the patient is dehydrated. The avoidance of dehydration is the essential factor in maintaining fluid bronchial secretions. Once hydration is achieved, humidification is relatively simple.

The use of these techniques will prevent the occurrehce of serious intrathoracic complications in almost all patients who present without intrathoracic abnormality and will control these complications in those who present with a "wet chest." They will also render bronchoscopy a rare event.

The management of infection and other intrathoracic complications in these patients is the same as in any other circumstances. Occasionally, unusual organisms will be found in the bronchial aspirate, for example $B$. Pyocyaneus. We have not seen such organisms cause any serious pulmonary or bronchial infection nor to persist in the bronchial secretions once the tracheotomy tube is removed, although rarely they are capable of causing serious pulmonary infection.

The Cardiovascular System. Congestive cardiac failure is recognized and treated in the usual way. It is not a contraindication to the use of I.P.P. which may, by providing adequate ventilation, relieve it.

Shock and hypovolemic states are particularly dangerous because many of these patients have cardiac disorders of various types-myocarditis trauma, arteriosclerotic heart disease, previous ischaemia of 'myocardium due tơ anoxia-rendering them liable to cardiac arrest from hypoxia. Further, I.P.P. aggravates the circulatory difficulties present in hypovolaemia, endangering renal function and exposing the patient to the risk of anoxic encephalopathy. Such states are dealt with in the usual ways, by vasopressors, blood transfusion, and arrest of haemorrhage. The use of a negative phase has been discussed above.

Pulmonary oedema may be the cause of a gradual or acute change in the otherwise satisfactory progress of many patients. It may be detected clinically and by a fall in tidal volume, with pressure constant machines, or by a rise in pressure with volume constant machines. I to a change in cardiac rhythm or in any post-thoracotomy or stove-in-chest patient from either atrial fibrillation or actual myocardial damage. Methods of management are not altered by I.P.P. which may in fact be advantageous. "Pulmonary oedema" has also been seen in the course of treating severe emphysema and this is discussed separately under that heading.

The Nervous System. The state of sensory deprivation $(98,99)$ occurs in these patients, particularly in those in whom there is interruption of the sensory pathway; it occurs less often in patients treated with I.P.P. than in those treated in tank respirators. Confusional states and deliria are not uncommon and when they occur some sort of restraint is usually necessary to prevent the patient interfering with the ventilator.

Anxiety and fear are inevitable in any conscious patient who needs artificial respiration and should be treated with full doses of appropriate drugs. The main 
factor limiting choice, dose, and routes of administration of drugs is their liability to produce hypotension. Meperidine is a frequent offender. Other factors are their liability to constipate and to cause addiction.

The care of paralysed limbs and the prevention of "trophic" lesions are important parts of the nursing routine. In the prevention of bedsores a "ripple mattress" is helpful but does not obviate the need for careful attention to pressure points and frequent turning of the patient. The care of the eyes may be overlooked in paralysed patients and in those who are unconscious for a long time. All such patients should be given antiseptic eye ointment prophylactically and if there is any facial weakness or any injection of the conjunctiva, an ophthalmic consultation should be sought at once. A tarsorrhaphy is quick and easy to do and undo, and will prevent disastrous ocular lesions.

Diet. Many patients are unable to swallow as a result of bulbar palsy, pseudobulbar palsy, or disturbance of consciousness, and many others need gastric or duodenal suction. Hence a duodenal tube is often needed for shorter or longer periods. Gastrostomy may be needed for oesophagitis or because of persistent bulbar palsy.

In the absence of dysphagia, patients should have a normal diet or a diet appropriate to their condition. If they need tube feeding, the diet must contain sufficient fluid, calories, vitamins, and minerals. An effective method is to homogenise a normal day's diet in a mechanical blender and to adjust its volume to provide 1 calorie/ml. This mixture is a fluid of unappetising appearance, high viscosity, and low salt content. Diluted appropriately, this has proved entirely satisfactory. The low salt content is an advantage rather than otherwise, as no special mixture is needed for patients with cardiac failure. Salt may be added as required for other patients.

Fluid Balance. In the adult a daily ( $24 \mathrm{hrs}$.) intake of $3 \mathrm{~L}$. is satisfactory but this volume may need to be altered according to the circumstances of any given case. Unless the volume and type of fluid ingested are charted, it is easy for these patients to become deficient, leading to drying of bronchial secretions and to electrolyte disturbances. The setting of ventilatory volumes is not exact and some overventilation is permissible in virtue of renal compensation. This margin is reduced by electrolyte disturbances. This is particularly important if ventilators without a patient-triggering device are used. Other frequently occurring complications that may be mentioned under this heading are paralytic ileus and constipation. They are managed in the usual ways.

Urinary Tract. Retention of urine is a common event and may need treatment by indwelling catheter. It is particularly important to avoid infection or to control it promptly. Two among many reasons may be emphasized: first, because such infections are commonly due tó gram-negative organisms and gram-negative septicaemia is a potent cause of hypotension and, second, because of the danger of calculus formation in the renal calyces in those who are recumbent for long periods. Large volumes of urine are an aditional protection against both infection and calculus formation. A further protection, in paralysed patients, is to nurse them on a rocking bed as soon as this is possible.

The Use of Drugs. In general, the use of drugs is not in any way affected by artificial ventilation. A few points are worth special mention. 
Sedatives can be used in full dosage without fear of interfering with ventilation by depression of the respiratory centre. In most of these patients, they should be used in sufficient dosage to induce amnesia for the acute stages of the illness and this should be explained to the patient's relatives. The main contra-indication to this use of drugs is the presence or danger of hypotension.

Drugs may be used in these patients in unusual ways and cause unexpected results. The best example of this is the use of nitrous oxide continuously for days on end in the treatment of tetanus and the production of agranulocytosis (100).

Muscle relaxants may be of great value and, provided that skilful nursing is available, there is no great danger in their use. There are two main indicationst for the use of relaxants: first, to abolish the convulsions of tetanus or status epilepticus, and second, to remove other causes of interference with artificial respiration. Tetanus and status epilepticus will be considered below and only muscular interference of other origin will be considered here.

Such interference occurs to some extent in all patients for a short while when assisted ventilation is begun. Most patients adapt themselves easily and quickly to the rhythm of the respirator provided that attention has been paid to minimizing the irritation of the tracheostomy tube and that sedation is adequate. A lew do not and their resistance to the ventilator may be such that it is impossible to overventilate them and reduce their stimulus to breathe. If this situation cannot be quickly controlled by simpler methods, then relaxants will permit the establishment of adequate ventilation and allow time for the patient to adapt himself to the situation.

A suggested indication is to remove part of the resistance to ventilation, not on account of the inability of the patient to co-operate but to reduce the pressure required to secure adequate ventilation. This situation arises in patients with some intrathoracic abnormality, of which by far the commonest is emphysema with or without bronchospasm, pneumonia, and excessive amounts of bronchial secretion. In these patients, the increased physiological dead space may require large tidal volumes. To secure these, high pressures and slow inspiratory flow are often needed, the mean intrathoracic pressure is therefore raised and the cardiac output may be reduced. It has been suggested that the elimination of the muscular component of the thoracic wall resistance to ventilation may enable the pressure to be reduced to levels that do not embarrass the circulation. There is evidence to suggest that reluxants will lower total resistance to inflation, possibly by abdominal relaxation. This indication must be regarded as still sub judice.

A third small group of patients in whom relaxants are useful are those with gross tachypnoea and consequent low tidal volumes. This is usually associated with pneumonia, occasionally with trauma to the chest and lungs. These conditions in themselves interfere with ventilation but the larger factor demanding respiratory assistance is exhaustion by the labour of inefficient respiration. In this group of patients, if narcotics prove ineffective or are contraindicated, the use of relaxants may have to be prolonged until the lesions stimulating the tachypnoea have resolved sufhicienty to permit adequate ventilation without paralysis.

There is a find group of pationts in whom reluxants may be useful. They are patients in whom adepluale ventation an onfy be achieved by assisted respira- 
tion but in whom adequate ventilation also permits them to be restless. This may occur in any condition of which a confusional state is a complication. Most such cases can be controlled by skilled nursing and sedation but, in some, sedation may be contraindicated and relaxants may be necessary to secure ventilation.

The choice of relaxant depends upon the probable time for which it will be needed and the undesirability of combining depolarising agents with competitive inhibitors. Both types of relaxant have been used for long and short-term cases. In general it is our practice to use short-acting compounds to establish artificial ventilation and longereacting compounds (laudexium) for other purposes. If succinylcholine is used for long periods, the concentration must be adjusted to avoid over-hydration; it is most conveniently given in a 1:500 solution. The rate at which this is infused may be altered to provide a required degree of paralysis. When prescribing relaxants for administration by nurses, no attempt has been made, with the exception of tetanus, to adjust the dose to the patient's response. A regular intramuscular dose has been ordered and any excess will be of little consequence during artificial respiration. Accumulation may occur; paralysis persisted for $24 \mathrm{hrs}$. beyond the last dose of laudexium in one instance. At that time, prostigmine was effective. The dosage of laudexium is $30-60 \mathrm{mg}$. intravenously to induce paralysis and $12 \mathrm{mg}$. intramuscularly repeated as often as necessary (e.g., every 2 hrs.).

The decision to use relaxants is not to be taken lightly. It introduces the complication of total paralysis into an already hazardous situation and interferes with physical examination. It should be remembered that auditory acuity is unaltered or enhanced during such states (101).

A last point in connection with the use of relaxants is one of diagnosis. As the effect of relaxants wears off and the patient starts to move, the first feeble movements are poorly co-ordinated and we have seen these diagnosed as almost any sort of involuntary movement from epilepsy to clonus.

The Restoration of Spontaneous Ventilation. Patients who have required I.P.P. for a few hours after taking a large dose of short-acting barbiturate present little difficulty. Their ventilation is easily measured and when it is adequate the respirator is disconnected in exactly the same way as the anaesthetist ceases to ventilate a patient after an operation.

In those who have needed I.P.P. for longer periods, two problems arise. The first is the patient's ventilatory ability, the second is psychological dependence on the respirator. The latter is dealt with by explanation, reassurance, and by permitting spontaneous ventilation initially for brief periods only. The most important measures are to wean the patient from the respirator only when his ventilatory ability is adequate and to ensure that the patient knows that the respirator can be reconnected at any moment.

The ventilatory measurements of most value are the tidal volume, respiratory rate, and vital capacity. They are more informative if recorded on a spirometer than as number of $\mathrm{ml}$., and have two purposes. The first is to determine whether the minute volume and tidal volume are adequate at the moment and the second is to determine the ventilatory reserve. This term is used to mean the difference between the tidal volume and the vital capacity. The latter is, of course, of 
limited significance, but it is easy to do and imposes little effort on the patient. Serial observations are essential.

In the patient without muscular weakness, the factors preclpitating respiratory failure, for example, excessive bronchial secretions, have been controlled, atelectasis, ileus, and pneumonic consolidation have been corrected, and the application of the principles set out above is then quite straight-forward. The problem is fundamentally to prevent a relapse, whether cardiac or respiratory.

In the patient recovering from paralysis, additional problems arise. Every physician who has looked after cases of poliomyelitis with respiratory paralysis is familiar with the danger of sudden death in these patients. This is likely to occur when they have been free of the respirator and apparently stable for some days or longer. The cause of death is unexplained but is probably sudden failure of the respiratory muscles. Because such fatigue is rapid (102), measurement of ventilatory volumes offers poor protection. Consequently, respiratory assistance must not be withdrawn too early. One very satisfactory method is gradually to transfer the patient from a respirator to a rocking bed (103) as the first step in his convalescence. As the vital capacity improves, the rocking bed may be turned off for gradually increasing periods. During these periods, the position of the patient should not hamper his ventilation. Thus a patient with diaphragmatic weakness should never be placed head-down unless he is being ventilated, whereas a patient with good diaphragmatic movement and weak intercostal and abdominal muscles is of ten better able to ventilate if he is placed slightly head-down, rather than strictly horizontal (104).

Rough guides, in adult patients, are that a vital capacity of $300-400 \mathrm{ml}$. will allow a patient to use a rocking bed but will not enable him to dispense with a respirator for long. A vital capacity of $400-600 \mathrm{ml}$. allows useful spontaneous ventilation for short periods and patients with vital capacities of $800 \mathrm{ml}$. and over usually do not need assistance unless some intrathoracic disorder occurs.

In the sections that follow, some of the main points in the management of the various groups, classified by diagnosis, (Table İ) will be discussed.

\section{Management of Neurological Disorders}

With the exception of tetanus, patients with diseases in this group present little difficulty in the management of assisted ventilation. The general principles outlined previously apply.

Drug Intoxication. Of the patients with respiratory insufficiency resulting from affection of the central nervous system, the largest group were those with barbiturate intoxication (Table I). These are the simplest group to manage and the principles and details are well recognized. The general opinion is that, provided a patient is not moribund when first seen, it is almost always possible to save his life. The essential points are the airway, adequate ventilation, the correctionef hypotension, the regulation of fluid and electrolytes, and other features of the care of the unconscious patient $(105,106)$. The main variables are the age and clinical state of the patient before ingestion of drugs and the nature and dose of the drug ingested. Once the airway is secure and adequate ventilation is established, the most urgent problem is to correct hypotension. Gastric lavage should 
not be performed and, if practicable, stimulants should not be given until the airway is protected by a cuffed endotracheal tube, lest aspiration of gastric contents should occur. Blood transfusion and infusion of plasma are sometimes recommended to restore satisfactory blood pressure. It must be, very rare that simpler measures such as pressor agents fail.

Lower Motor Neurone Lesions. This group includes poliomyelitis, polyneuritis, myasthenia gravis, certain metabolic disorders such as hypo- and hyper-potassaemia, and certain muscular disorders, particularly polymyositis.

Underventilation may be caused by airway obstruction due to bulbar palsy, by weakniess of the respiratory muscles, or, rarely, in poliomyelitis by damage to the medullary centres. Atelectasis, pneumonia, and pulmonary oedema may aggravate any such respiratory embarrassment and are particularly likely to occur if there has been any delay in the recognition and institution of proper treatment of bulbar palsy.

The clinical diagnosis of both bulbar palsy and respiratory impairment (107) have been widely discussed in the recent literature and will not be considered in detail here. Respiratory failure is not of abrupt onset in these conditions. The clinical problem is to assess the extent to which ventilatory function is affected, to follow its changes by serial observations, and to institute appropriate treatment in good time. Respiratory insufficiency, as judged by alterations in $\mathrm{pCO}_{2}$, is not present until 80 or 90 per cent of the ventilatory function is destroyed. Hence, arterial $\mathrm{pCO}_{2}$ levels will be of no value and if anxiety has led to overbreathing, the $\mathrm{pCO}_{2}$ may be low when the ventilatory reserve is already greatly diminished. The most convenient method in practice is to measure the vital capacity twice daily or more often if necessary. If appropriate apparatus is not available, a useful rough guide to the vital capacity is to ask the patient to count aloud, at the rate of two digits a second, as high as he can in one breath. Ten digits is approximately equivalent to a vital capacity of $1 \mathrm{~L}$. More elaborate methods of investigating respiratory function are often either impossible or contraindicated.

In yery general terms, if the vital capacity is less than 50 per cent of the predicted normal, a respirator should be available and if less than 30 per cent of the predicted normal it is likely to be needed. In cases of poliomyelitis, to avoid fatigue of the respiratory muscles, it should be used when the vital capacity is less than 30 per cent of the predicted normal.

Bulbar palsy and the consequent accumulation of pharyngeal secretions may be dealt with, if isolated, by postural drainage. This is easier to manage in children than in adults. It should not be attempted if there is any diaphragmatic weakness lest the additional work required of the respiratory muscles lead to sudden respiratory failure. Paralytic ileus and severe pain in poliomyelitis and polyneuritis often make it impossible to impose on the patient the additional discomforts of lying prone or head-down and a cuffed tracheostomy tube will frequently be preferred.

The problems of respiratory insufficiency due to paralysis are more complicated in myasthenia gravis. The paralysis is variable and may change rapidly. Sudden fatigue of the respiratory muscles is the problable cause of the sudden death that is notorious in this condition (108). Secretions are apt to be more profuse as a 
result of anticholinesterase therapy, which may also cause respiratory paralysis. These factors are present in any case of moderately severe myasthenia gravis and are aggravated by the hazards of sternotomy after thymectomy. These can be reduced if a tracheotomy is done, through a separate incision, at the time of thymectomy; and if anticholinesterases are witheld in the immediate postoperative period. Respiratory insufficiency can then be easily handled by the respirator and the correct dose of anticholinesterases re-established in the usual way. This method of managing the severe case of myasthenia gravis undergoing thymectomy is satisfactory, but it demands experience of the illness, of postoperative management, and of I.P.P.

Spinal Cord Lesions. The consequences to respiratory function of spinal eord lesions depend on the situation of the lesion. If the segments giving rise to the phrenic nerve, usually $\mathrm{C} 3,4,5$, are damaged, then inspiration, expiration, and coughing will be impaired. If the lesion spares these segments or roots, then only active expiration and coughing will be affected. In the latter case, the expiratory reserve volume is diminished; in the former, inspiratory reserve volume is diminished also.

Clinically, therefore, the consequences are a liability to rétention of bronchial secretions, atelectasis, and pneumonitis in all cases, as well as underventilation in some. The pessibility of underventilation is increased by the frequent occurrence of paralytic ileus. In the later stages, the situation is sometimes complicated by spasticity of the trunk muscles.

Most of the patients whom we have seen with respiratory insufficiency due to cervical cord lesions are cases of injury of ten complicated by chest (vide infra) and head injuries, both of which may hamper respiration still further. The situation under these circumstances needs 'very careful neurological, surgical, and respiratory supervision.

A final diagnostic point is the occurrence of minor cervical cord injuries in patients whose major injury is to some other part, usually the head, sometimes the chest (109). In many cases these injuries to the cord occur in patients with cervical spondylosis (110) and a characteristic feature, not always present, is the presence of spasticity in the acute phase. This injury may account for respiratory embarrassment which is otherwise difficult to explain.

The injured neck is most conveniently immobilized by ice-tong traction or, in cases of minor injury, by placing the head between sand bags:

Tetanus. In Western Europe and North America, tetanus is a relatively rare disease and large series come mostly from lands with less lavish medical facilities in which the use of modern methods of assisted respiration are not widely available. The use of relaxants and artificial respiration in tetanus is an innovation in treatment and has been of widespread interest $(111-114)$. Their place is by no means established.

The theory is that tetanus is a self-limited disease and, if it is not fatal, the patient will make a complete recovery. This view is not altogether certain in very severe cases and there is evidence to suggest that sometimes tetanus is "inevitably" fatal. Secondly, in a very large series, over many years, there has been a steady fall in the mortality not related to any particular treatment. Thirdly, other 
methods of treatment are very effective (115). In seven years at the Toronto General Hospital, there have been ten cases/with one death. This was in a very unpromising therapeutic prospect, who died of staphylococcal septicaemia, but was the only case treated by relaxants and I.P.P.

The place of relaxants and I.P.P. is therefore with only the most severe cases, but in some of them it may be lifesaving. The indications for its use are not clear (116). One group took as an indication the occurrence of a spasm that stopped ventilation.

The situation is complicated by a number of factors, the first of which is that little is known of ventilatory function in tetanus. Partial laryngeal obstruction due to spasm, aggravated by efforts to swallow or speak, is common, and it is the usual practice to do a tracheostomy in any case of generalized tetanus. Another important factor is that inspiration produces reflex spasm of the expiratory muscles and, hence, shallow respirations. Another is that the spasm of muscles increased the need for oxygen. The dangers of underventilation are great, particularly as a cardiopathy similar to thąt of diphtheria has been reported in severe cases of tetanus.

The most satisfactory regimen in a case of generalized tetanus may prove to be early tracheostomy, a constantly maintained level of sedation and a fine adjustment, so to speak, with shortacting intravenous barbiturates, phenothiazines, or meprobamate (117-120). This requires the almost constant presence of a physician. If it proves impossible to control the spasms and allow adequate spontaneous respiration by these means, then relaxants and I.P.P. should be used.

Relaxants or sedation may be needed continuously for three weeks. The appropriate daily dosages vary but are remarkably constant in any one patient. There is, in any patient receiving I.P.P., some variability in the resistance to ventilation, depending on the accumulation and removal of bronchial secretions, on changes of posture, and on residual muscular power. These do not in the usual case cause very much difficulty. In tetanus, as the effect of relaxants wanes, there may be-considerable alterations in resistance and extra vigilance is needed to ensure that correct tidal and minute volumes are achieved. This is, therefore, an excellent indication for a volume-constant ventilator; changes in pressure are then taken to indicate the need for suction or for change in relaxant dosage.

In emphasizing the uncertainties and difficulties in the use of this method of treating tetanus, it should not be overlooked that there are a number of advantages. Spasms are abolished, sedation can be lighter, and there is less danger of extreme hypotension and hypoxia. The nursing care of the patient is easier because the same urgency does not attach to reducing the number of stimuli received by the patient. With well-trained nurses, the constant attendance of a physician is not needed.

\section{Management of Emphysema}

Underventilation associated with emphysema is, in our experience, most difficult to manage. The problems are those of complex and incompletely understood alterations of pulmonary p̉hysiology associated with extensive destruction of lung. 
These patients frequently present with severe respiratory insufficiency as a result of a complicating factor, usually infection, but occastonally the incautious: use of opiates or oxygen, or myocardial ischaemia.

A proportion of these patients may be returned to a contented life by caref/hl treatment-rest in bed, nursing, antibiotics, steroids, bronchodilators, digita $/$ s, diuretics-and assisted ventilation provides the opportunity to attempt this In any particular case, prognosis is most difficult. It will depend, to a large extent, upon the relative importance of the basic pulmonary pathology and of the complicating factors. Thus, a knowledge of the detailed history will be most valuable.

The table shows our experience with 23 cases, 8 of whom died. The average length of stay was 24 days and assisted respiration was required for an average time of two weeks. None was admitted until less drastic therapy had been unsuccessful and, in this regard, the use of Nikethamide continuously rather than I.P.P. is of great interest.

The complex problems involved in these cases may be summarized thus:

(a) Carbon dioxide retention. These patients are frequently accustomed to high arterial $\mathrm{CO}_{2}$ tensions in the range of $45-60 \mathrm{~mm}$. $\mathrm{Hg}$. Additional acute $\mathrm{CO}_{2}$ retention may raise the level to $110 \mathrm{~mm}$. Hg. or more. Neither disorder of consciousness nor any other clinical sign has been found to correlate well with levels of arterial $\mathrm{CO}_{2}$ but disorientation is usual at levels over $90 \mathrm{~mm}$. $\mathrm{Hg}$.

(b) Hypoxia. Although much attention has been given to the effects of $\mathrm{CO}_{2}$ retention in emphysema, the commonly associated hypoxia deserves equal or greater respect. The relative degree of hypoxia or hypercarbia varies from case to case and oxygen administration must be carefully controlled, to avoid further $\mathrm{CO}_{2}$ retention, if respiration is not assisted.

When underventilation occurs, hypoxia may cause cerebral dysfunction, myocardial ischaemia with hypotension and subsequent ECG changes, renal ischaemia with oliguria, and, possibly, gastro-intestinal ischaemia as shown by paralytic ileus and gastric dilatation. In the acute phases, it has been considered advisable to assist respiration with 100 per cent $\mathrm{O}_{2}$. Once ventilation has been established satisfactorily, 40 per cent oxygen is used, this being the minimum delivered by the intermittently opening reducing valve type of machine commonly used in the management of these cases. I.P.P. by tracheotomy is one of the few ways in which 100 per cent $\mathrm{O}_{2}$ may be delivered to thè alveoli and the dangers of oxygen intoxication must be remembered.

(c) Cardiac failure. Emphysema progressing to the stage requiring ventilatory assistance is very frequently associated with right heart failure and fluid retention (121). This appears to be secondary to the inability of the myocardium to overcome a raised pulmonary vascular resistance. It has been noticeable that failure resistant to routine therapy may reverse within a very few days, once respiratory assistance is initiated. It is assumed that this is related predominantly to an improved arterial oxygen tension, producing a reduced pulmonary vascular resistance and increased myocardial efficiency.

In the present series, left heart failure has been seen following myocardial infarction, with pulmonary congestion sufficient to produce respiratory insuf- 
ficiency in an emphysematous patient. A small group of cases have simulated left heart failure terminally. The pattern in this last group has been as follows: a patient with severe emphysema has developed acute respiratory insufficiencyusually associated with hypotension, hypoxia, and depression of level of consciousness. With vigorous ventilatory treatment, the arterial $\mathrm{pCO}_{2}$ has been reduced, and the level of consciousness, colour, and general condition markedly improved. After two or three days of such progress, hypotension and fine crepitations have appeared. Death has resulted. At autopsy, the picture has been obscure but most closely resembles the effects of experimental oxygen toxicity. The lungs have been grossly congested and microscopically the alveoli have contained red blood cells. Pulmonary oedema was not present. The alveoli have undergone "foetalization," that is, have become lined with cuboidal epithelium. It is felt that the last finding relates to the 100 per cent oxygen given to these patients for the preceding few days. While the congestion may also be the result of oxygen toxicity, other possibilities are left heart failure, possibly due to a previously anoxic left ventricular myocardium suddenly being presented with a much elevated input, resulting from the improved ventilation and oxygenation, or to trauma from I.P.P. on abnormál lungs.

(d) Neurological accompaniments. The neurological symptoms which may be associated with chronic respiratory disease are disorders of consciousness, papilloedema, hẹadache, involuntary movements, and rigidity. No characteristic neuropathological findings have been established. The genesis of these symptoms is not certain, but as well as $\mathrm{CO}_{2}$ narcosis and hypoxia, ammonia intoxication has been suggested. The most common symptoms in our experience have been disorders of consciousness and of behaviour, which do not differ from similar disorders seen in other encephalopathies. Variable rigidity is a usual accompaniment of these symptoms. Involuntary movements, most frequently twitching of muscles on maintaining a posture, have been common. In some patients, the typical movements of asterixis have been present and as the patient improves the twitching is all that remains of this. Occasionally, we have observed gross clonic movements similar to the myoclonic jerks of epileptics and have taken this to be an indication to use anticonvulsants. Papilloedema has been the rarest of the neurological signs.

With correction of the ventilatory defect, the neurological signs improve, papilloedema and the disorder of consciousness disappear although it may take some months for the latter to do so completely. The usual complaint, in those in whom it does not clear up and in whom spontaneous ventilation is adequate, is that they are difficult and touchy. We have not seen any gross social incapacity from persisting confusion, defects of memory, or dementia. Similarly, the involuntary movements have improved. Although minor degrees of twitching may still be present on formal examination, they are not then a symptom of which complaint is made.

The ventilatory requirements are a high tidal volume, to overcome the dead space, delivered slowly enough not to exaggerate the distribution defect, and a long expiratory phase to permit maximum emptying and to produce a low mean intrathoracic pressure. Clearly, the higher the tidal volume the longer the expira- 
tory phase that will be required. In one small series a negative phase did not prove of value (25) and the danger of this phase aggravating trapping has been pointed out (92). In practice, one is frequently hard put to produce adequate ventilation. One requires a machine with wide phase adjustability and, measuring ventilation continuously, phases and volumes are adjusted to produce maximum ventilation with minimal trapping. This can be detected simply: (i) expiration is observed on the gas meter and if inflation starts/while expired gas is still flowing, trapping is occurring and must be corrected. (ii) This may be confirmed by ausculation of the chest. A needle may be placed in the external jugular vein and connected to tubing filled with heparin and saline. Venous pressure may then be observed continuously and the ventilation adjusted to produce the lowest level possible.

The resistance to inflation may be high especially when significant bronchospasm, pneumonia, left heart failure, or pulmonary fibrosis are present. Thoracic wall compliance may be low and, when marked distress exists, tachypnoea may further hamper ventilation. Patient-triggered respiration, set at pressures which produce adequate tidal volumes, may slow the rate. However, if the slowing is insufficient to prevent trapping, small doses of intravenous narcotic may be beneficial. If this is ineffective, or when it produces hypotension, one may paralyse the patient with muscle relaxant. This is a serious and somewhat retrograde step and, although used in four instances in the present series, its necessity is of grave prognostic import. In all cases, ventilation will be improved by the efficient aspiration of secretions, which may bê assisted by the use of bronchodilators and vasoconstrictors delivered by nebulizer.

Essentially, the management of emphysema involves vigorous and meticulous routine measures, with ventilatory assistance where death could result without it. This description does not refer to cases of emphysema in which I.P.P. is used solely as a means of delivering nebulized medications to the bronchial tree.

Three different methods of giving assisted respiration in emphysema have been assessed recently, I.P.P. being preferred to tank and cuirass respirators (122).

\section{Management of Post-Operative Respiratory Insufficiency}

Patients unable to breathe following surgery fall into two broad groups: (i) those with temporary, easily reversible problems such as persistent curarization, excessive cental depression, either by general anaesthesia or by narcotics, pneumo-thorax, haemothorax, atelectasis, and so on, and (ii) those with states considerably more resistant to correction. It is with the second group that we are primarily concerned. These patients almost always have some form of preexisting respiratory defect to which the effects of surgery are added. Another group are those who have undergone neurosurgery or sustained head injuries with resulting damage to respiratory pathways and who may be treated in the same way as any other central nervous system lesion (123).

The limitations imposed by surgery are those of pain in the abdomen and thorax, tight dressings, abdominal distension, and various intrathoracic disorders. Among the latter, disorder of thoracic wall movement following thoracotomy, broncho-pneumonia, and atelectasis are well recognized. Changes in pulmonary 
function following thoracotomy and I.P.P. have been described and the deterioration in diffusion emphasized (17). Distribution is also said to be impaired and, following muscle relaxants, the decreased thoracic and, hence, lung volume is said to lead to poor expansion and perfusion in peripherally placed lobules. This obviously depends upon many variables.

One group which has not received atterition in the literature includes those with poor thoracic movements because of age, debility, toxicity, and so on. It has been noted that these patients behave very like those with muscular weakness produced by poliomyelitis or myasthenia, for example. Thus, after relatively good respiratory efforts for a period, they may quickly become exhausted and even apnoeic.

Essentially, the treatment consists of tiding the patient over until the limitations added by surgery resolve. In the absence of an obviously reversible complication, the patient with a chronic respiratory disorder, breathing inadequately after surgery to chest or abdomen, will usually require several days respiratory assistance. Early recognition of this situation is therefore important. Repeated failed trials of spontaneous respiration frequently change a-mild to a serious situation as a result of recurrent bouts of hypoxia and hypercarbia.

Features peculiar to cardiac surgery. Pulmonary lesions occurring after cardiac surgery frequently produce hypoxia and the need for adequate oxygenation is paramount. The myocardium and its conduction mechanism are extremely sensitive to hypoxia at this stage.

Many patients with the respiratory embarrassment of chronic left heart failure pass through the first few post-operative days on the brink of respiratory insufficiency. Inability to cough. up secretions frequently necessitates tracheostomy with or without I.P.P.

Following surgery for conditions associated with pulmonary hypertensionmitral valve disease, atrial and ventricular septal defects-and especially when extracorporeal circulation is used, respiratory insufficiency is among the most common causes of death. This appears to occur in two forms: (i) diffusion defects without, copious sputum and without marked clinical or radiological evidence of changes in the lung fields. Such patients benefit from 100 per cent oxygen, administered via tracheostomy by I.P.P., and (ii) the respiratory insufficiency. syndrome, characterized by patchy pulmonary congestion, copious sputum, severe respiratory distress, and rapid progression to death. While this can be avoided to some extent by selection of patients and by extracorporeal technique, once the situation has arisen its course can often be reversed by I.P.P.

Whatever the cause, any increased work of breathing may be dangerous in a patient with a damaged myocardium and, in this group, ventilatory assistance should be considered early. Tachypnoea and high total resistance may indicate the use of relaxants and a volume-constant machine. An occasional indication for assisted ventilation occurs when deficient respiration prevents adequate compensation for metabolic acidosis. This has been seen in pneumonia accompanying gross oliguria and is not uncommon following cardiac surgery, particularly when hypothermia or extracorporeal circulation have been used. 


\section{Management of Pneumonia}

In our experience, pneumonia has led to ventilatory insufficiency in the following circumstances: (i) as a complication of pre-existing respiratory disease, for example, emphysema; (ii) post-operatively; (iii) in staphylococcal pneumonia; and (iv) when coexisting with metabolic acidosis.

Carbon dioxide retention is relatively rare in pneumonia but each of the first two groups has added reason for hypercarbia. Those patients with staphylococcal pneumonia have developed serious trouble due to crusting of secretions within the bronchial tree. Certain points are significant:

(a) Oxygenation. This group causes great anxiety in this regard. Venous admixture, poor diffusion, and, in many instances, disturbances in distribution all lead to low arterial $\mathrm{O}_{2}$ tension without $\mathrm{CO}_{2}$ retention. In fact, the tachypnoea of pneumonia may produce hypocarbia. Oxygen must be added to the inflation gases in quantities adequate to produce an oxygen saturation as near normal as possible.

(b) Tachypnoea. The extreme tachypnoea sometimes seen may limit tidal volume to an extent where alveolar ventilation falls. Intravenous narcotics may: prove helpful, but in extreme cases muscle relaxants may be required. The tachypnoea may produce exhaustion and death, and is an indication for early assisted ventilation.

(c) Resistance to ventilation. This is raised and ventilators with high maximum pressures may be required to ventilate patients with extensive disease. Experience has shown that even in gross multilobar consolidation adequate ventilation can be achieved by such equipment.

(d) Bronchoscopic equipment. Emergency bronchoscopy has become a very rare procedure in the Toronto General Hospital unit, with the exception of staphylococcal pneumonia, where plugs too large for suction equipment may have to be removed with grasping forceps. This is particularly liable to occur when the tracheo-bronchial mucosa is destroyed by infection, as in post-influenzal pneumonia.

\section{Management of Stove-In-Chest}

The use of I.P.P. in stove-in-chest has revolutionized its management (78). Death from asphyxia is prevented, pain is controlled, and mechanical devices to support the thoracic cage are eliminated, as the chest wall is uniformly supported by the intermittent intrathoracic positive pressure.

While conservative management is satisfactory in certain of these cases, this will usually be the exception when paradoxical movement of the chest wall occurs. Shortly after injury only relatively minor degrees of paradox may be present but, uncorrected, this is sometimes progressive and leads to gradual deterioration. We have twice seen neglect of such minor degrees of paradox lead to death from cardiac arrest.

The immediate requirements are to secure an airway and to control ventilation. The patient is intubated, usually under general anaesthesia, and ventilation is begun. Control is achieved by overventilation until respiratory alkalosis is 
sufficient to remove the $\mathrm{CO}_{2}$ stimulus to spontaneous respiration. This may be expedited by one dose of muscle relaxant at the outset. The degree of overventilation is adjusted to the point where any reduction in minute volume is followed by spontaneous respiratory efforts. Oxygen in percentage higher than that in room air may be required. No advantage has been found in using uncuffed tubes and any machine capable of delivering stroke volumes up to $1 \mathrm{~L}$. may be used satisfactorily with cuffed tubes.

'When satisfactory ventilation is secured, other conditions are searched for and dealt with (124). Air or blood in the pleural or pericardial cavities, gastric dilatation and paralytic ileus, abdominal injuries, head injuries, whip-lash injuries, and fractures and dislocations around the shoulder girdle are common. An ECG will often reveal evidence of myocardial injury, sometimes with an associated atrial arrhythmia. A chest X-ray should be taken as early as possible and usually shows extensive pulmonary mottling due to intrapulmonary haemorrhage.

When ventilation has been established and the patient examined, and when other conditions have been dealt with and the patient's general condition improved by transfusion and whatever other measures are needed, tracheostomy is done.

These pațients are nursed on a ripple-mattress in a semi-sitting position and are the exceptions to the rule that those needing artificial respiration are turned frequently. Turning is very painful and delays union.

The presence of intra-alveolar blood is taken as an indication for prophylactic antibiotic therapy. Such patients are pyrexial and the onset of infection is difficult to detect. Other conditions arising from this type of injury are dealt with on their merits, irrespective of the need for assisted respiration.

The chest becomes stable in from 10 to 30 days, depending largely on the severity of the injury and the age of the patient. I.P.P. should be continued until paradox is absent or very minimal, or some deformity of the chest wall will result.

\section{Transpótation of Patients with Respiratory Insufficiency}

Patients with respiratory inadequacy' have travelled all over the world, assisted by cabinet respirators or I.P.P. The latter lends itself particularly well to this purpose, as the equipment does not require much space and is easily portable.

For transportation, one requires a clear airway, suction equipment, and a method of applying I.P.P.

(a) Airway. Endotracheal intubation remains the method of choice, requiring only simple equipment readily available in most hospitals. Adequate topical anaesthesia at the outset and subsequent administration of sedation and cough depressants render the tubes tolerable.

It has been suggested that intubation may convert a "dry" to a "wet" chest (125). This has not been our experience, although marked salivation and bronchial secretion occur in association with distress and objection to the tube. Adequate 
sedation, topical anaesthesia, and efficient suction have proved satisfactory in avoiding this.

(b) Suction equipment. Portable equipment may be obtained which runs off compressed air, D.C. battery, or foot pump. Catheters for use with endotracheal tubes should be longer than ordinary urethral types and special endobronchial suction catheters are available. In their absence a shortened duodenal tube may be better than a urethral catheter.

(c) I.P.P. equipment. For short periods, a bag and non-return valve may be used with a source of oxygen. Alternatively, a self-inflating bag may be used with air. For longer journeys, mechanical respirators are available, working from D.C. batteries.

The practice of transporting a patient with inadequate respiration with an unsecured airway and no means of ventilation or suction is very dangerous.

\section{RESULTS OF TREATMENT}

This article is concerned with a discussion of method. For this reason and because, with some notable exceptions, the numbers of cases of any one condition yet reported areismall, a detailed consideration of prognosis would be out jof place. This section will, therefore, be confined to a discussion of the results in 1 go consecutive admissions to the Respiratory Unit of the Toronto General Hospital. (See Table I.)

The first consideration in assessing results is the selection of cases. This has depended in the first place on the referring physician. In general, the cases that have been referred have been ones of underventilation as a result of disorders that carry a fairly good prognosis and ones of undiagnosed disease, not those resulting from progressive and mortal illness or from illness that directly destroys the mind and personality. Hence, if the patient can be tided over the period of underventilation, the prognosis is that of the primary condition and is not allered by the fact that artificial respiration has been necessary. The possibility that a patient will never become free of the need for respiratory assistance is often present, of course, and of the 75 survivors, one, a myasthenic, needs help from the rocking bed for some part of each day.

Emphysema is to some extent a special case in that the fundamental lesion is progressive. In common with all who have treated cases of emphysema in this way, we have been impressed by the difficulty of predicting the outcome once the need for respiratory assistance is over. In some, we have been surprised by the improved and relatively excellent health of the patient; in others there has been no significant improvement. We have not found it possible to predict into which category any given patient would fall.

With the exception of patients with neurological disease, in whom the possible need for artificial respiration has long been stressed, the use of these techniques is relatively unfamiliar. Hence, patients are of ten not referred until they are thought to be dying. While it, is true that artificial respiration is hazardous and not to be entered into lightly, and that skilful man agement of those on the brink 
of underventilation will sometimes avoid the necessity for its use, it is no less a part of skilful management to institute artificial respiration before an urgent situation has become desperate.

The causes of death are set out in Table I. The largest group, the patients with emphysema, were considered above. Of the patients with cardiac arrest, three followed cardiac surgery; one was the consequence of not giving I.P.P. to a patient with a stove-in-chest and the other was the result of intracranial haemorrhage.

TABLE I

\begin{tabular}{|c|c|c|c|c|c|}
\hline & Diagnosis & Treate & arvived & Died & Cause of death \\
\hline \multicolumn{6}{|c|}{ Neurological disorders } \\
\hline \multirow{5}{*}{ Central } & Drug intoxication & 16 & 15 & 1 & Anoxia \\
\hline & Intracranial aneurysm & 1 & 0 & 1 & Cardiac arrest \\
\hline & Anoxia from drowning & 1 & 0 & 1 & G.I. haemorrhage \\
\hline & Disseminated sclerosis & 2 & 2 & 0 & \\
\hline & Cervical cord injury & 5 & 4 & 1 & Haemorrhage, traumatic \\
\hline \multirow[t]{4}{*}{ Peripheral } & Myasthenia gravis & 7 & 6 & 1 & Haemorrhage, secondary \\
\hline & Peripheral neuropathy & 4 & 3 & 1 & Pneumonia \\
\hline & Poliomyelitis & 1 & 1 & 0 & \\
\hline & Hyperpotassaemic paralysis & 1 & 0 & 1 & $\begin{array}{l}\text { Renal failure (subac. } \\
\text { glomerulonephritis) }\end{array}$ \\
\hline \multirow{2}{*}{ Curare } & Status epilepticus & 3 & 2 & 1 & Anoxia \\
\hline & Tetanus & 1 & 0 & 1 & Pneumonia \\
\hline \multirow{2}{*}{$\begin{array}{l}\text { Emphysema } \\
\text { Post-thoracotomy }\end{array}$} & & 23 & 15 & 8 & \\
\hline & Cardiac & 9 & 5 & 4 & $\begin{array}{l}\text { Cardiac arrest-3 } \\
\text { Renal failure (follow- } \\
\text { ing shock) }-1\end{array}$ \\
\hline \multirow{3}{*}{$\begin{array}{l}\text { Post-laparotomy } \\
\text { Chest Injury }\end{array}$} & Pulmonary & 1 & 1 & 0 & \\
\hline & & 8 & 6 & 2 & Peritonitis \\
\hline & Stove-in-chest & 8 & 7 & 1 & Cardiac arrest \\
\hline \multirow[t]{2}{*}{ Miscellaneous } & Status asthmaticus & 1 & 1 & $\begin{array}{l}1 \\
0\end{array}$ & Pneumon1a \\
\hline & Post-influenzal pneumonia & & & & \\
\hline \multirow[t]{2}{*}{ Observation } & $\begin{array}{l}\text { (Staph. aureus) } \\
\text { Need for I.P.P. avoided }\end{array}$ & $\begin{array}{l}1 \\
5\end{array}$ & $\begin{array}{l}1 \\
5\end{array}$ & $\begin{array}{l}0 \\
0\end{array}$ & \\
\hline & & $\overline{100}$ & $\overline{75}$ & $\overline{25}$ & \\
\hline
\end{tabular}

Three patients died of pneumonia and in two of them the infection might be counted as a failure of the technique of treatment.

Cerebral anoxia was the cause of status epilepticus in two cases admitted for this condition and resulted in the death of one. Another case of anoxia was due to hypotension, prior to admission to hospital, from an overdose of seconal.

Haemorrhage from the denuded mucosal surface of the upper gastro-intestinal tract, resulting from ingestion of carbolic acid, was the cause of death in the patient admitted following a double attempt at suicide, by poisoning and drowning. The other cases were due to rupture of the spleen and to secondary haemorrhage following thymectomy.

Of the survivors, about whom information is available, the great majority are back at their normal occupations. In three patients it has not been possible to close the tracheostomy. Two, one with poliomyelitis, and one with myasthenia gravis, have persisting bulbar palsy. The first is working at the job he had before his illness, the second is still in hospital needing periods of assisted respiration. 
The third, with emphysema, leads a contented life of iretirement. Those who have not returned to their usual occupations are the cases of disseminated sclerosis and of cervical cord injuries. These patients have followed the course usual in those conditions and have done perhaps rather better than most. Other than the two patients with granulomata of the vocal cords referred to above, no sequelae attributable to I.P.P. have been observed.

\section{SUMMARY}

The management $\operatorname{of}_{z}$ patients with respiratory insufficiency, using intermittent positive pressure, has been discussed in detail. Emphasis has been laid on the underlying physiological problems and on the need for detailed specialized knowledge.

The available equipment and methods of use are discussed, together with methods of monitoring assisted respiration. Problems of diagnosis of underventilation, general principles of management and the problems associated with the more common causes of respiratory insufficiency are discussed.

\section{ACKNOWLEDGMENTS}

The authors wish to acknowledge the contribution of their colleagues on the attending staff of the Toronto General Hospital Respiratory Unit, Drs. H.I O. Barber and C. R. Woolf. They also wish to thank Dr. C R. Woolf for assistance and advice in preparing the manuscript and Dr. H. J. Barrie for his opinion on the morbid anatomy of emphysematous lungs, following intermittent positive pressure respiration.

\section{REFERENCES}

1. II KINGS 4: 32-34.

2. Drinker, C. K. Pulmonary Oedema and Inflammation. Cambridge, Mass.: Harvard Univ. Press (1945).

3. Drinker, P., \& Shaw, L. A. An Apparatus for the Prolonged Administration of Artificial Respiration. 1. A Design for Adults and Children. J. Clin. Invest. $7: 229$ (1929).

4. BraGG, W. H. Bragg-Paul Pulsator. Brit. Med. J. ii: 254 (1938).

5. Kelleher, W. H.; Wilson, A. B. K.; Russel, W. R.; \& Stott, F. D. Notes on Cuirass Respirators. Brit. Med. J. 2: 413 (1952).

6. Eve, F. C. Actuation on the Inert Diaphragm by a Gravity Method. Lancet 2: 995 (1932).

7. LAssen, H. C. A. A Preliminary Report on the 1952 Epidemic of Poliomyelitis in Copenhagen with Special Reference to the Treatment of Acute Respiratory Insufficiency. Lancet $1: 37$ (1953).

8. Barber, H. O.; Chambers, R. A.; Fairley, H. B.; \& Woolf, C. R. A Respiratory Unit. Canad. M.A.J. $81: 97$ (1959).

9. Comroe, J. H., Jr.; Forster, R. E., II; Dubois, A. B.; Briscoe; W. A.; \& Carlsén, E. The Lung. Chicago: Year Book Publishers (1955).

10. Nunn, J. F. Physiological Aspects of Artificial Ventilation. Brit. J. Anaesth. 29: 540 (1957).

11. Briscoe, W. A., Forster, R. E., \& Comroe, J. H., Jr. Alveolar Ventilation at Very Low Tidal Volumes. J. Appl. Physiol. 7: 27 (1954).

12. Woolmer, R. The Management of Respiratory Insufficiency. Anaesthesia 11:281 (1956). 
13. Doвkin, A. B. Regulation of Controlled Respiration: Recent Concepts of Importance to the Anaesthetist. Brit. J. Anaesth. 30:282 (1958).

14. Radford, E. P., Jr., Ferris, B. G., \& Kriete, B. C. Clinical Use of a Nomogram to Estimate Proper Ventilation During Artificial Respiration. New Eng. J. Med, 251: 877 (1954).

15. Hertzog, P., \& Engstrom, C. G. In Mushin W. W. et al., Automatic Ventilation of the Lungs. Oxford: Blackwell (1959).

16. Campbell, E. J. M., Nunn, J. F., \& Pechett, B. W. A comparison of Artificial and Spontaneous Respiration with Particular Reference to Ventilation-Blood Flow Relationships. Brit. J. Anaesth. 30: 166 (1958).

17. Schramel, R. J.; Cameron, R.; Ziskind, M. M.; Adam, M.; \& Creech, O., Jr. Studies of Pulmonary Diffusion after Open Heart Surgery. J. Thorac. Surg. 38: 281 (1959).

18. Otis, A. B. The Work of Breathing. Physial. Rev. 34: 449 (1954).

19. Mcllroy, M. B., Marshall, R., \& Christie, R. V. The Work of Breathing in Normal Subjects. Clin. Sci. 13: 127 (1954).

20. Cook, C. D., Helliesen, P. J., \& Agathon, S. Relation between Mechanics of Respiration, Lung Size and Body Size From Birth to Young Adulthood. J. Appl. Physiol. 13: 349 (1958).

21. Swyer, P. R. The Problem of Prematurity. Canad. M.A.J. '82: 347 (1960)!

22. Nims, R. C., Connor, E. H., \& Comroe, J. H., Jr. The Compliance of the Human Thorax in Anaesthetized Patients. J. Clin. Invest. 34: 744 (1955).

23. Butlér, J., \& Suith, B. H. Pressure-Volume Relationships of the Chest in the Completely Relaxed Anaesthetised Patient. Clin. Sci. 16:125 (1952).

24. Howell, J. B. L., \& Peckett, B. W. Studies of the Elastic Properties of the Thorax of Supine Anaesthetized Paralyzed Human Subjects. J. Physiol. (Lond.) 186: 1 (1957).

25. Opie, L. H., Spalding, J. M. K., \& Stort, F. D. Mechanical Properties of the Chest During Intermittent Positive Pressure Respiration. Lancet 2: 545 (1959).

26. Gliedman, M. L.; Siebens, A. A.; Vestal, B. L.; Timmes, J. J.; Grant, R. N.; Murphy, J. L.; \& Karlson, K. E. Effect of Manual Versus Automatic Ventilation on the Elastic Recoil of the Lung. Ann. Surg. 148: 899 (1958).

27. Opie, L. H., Smith, A. C., \& Spalding, J. M. C. Concious Appreciation of the Effects Produced by Independent Changes of Ventilation Volume and of End-tidal $\mathrm{pCO}_{2}$ in Paralysed Patients. J. Physiol. (Lond.) 149: 494 (1959).

28. Crane, M. G.; Affeldt, J. E.; Austin, E.; \& Bower, A. G. Alveolar Carbon Dioxide Levels in Acute Poliomyelitis. J. Appl. Physiol. 9: 11 (1956).

29. Couríand, A.; Motley, H. L.; Werko, L.; \& Richards, D. W., Jr. Physiological Studies on the Effects of Intermittent Positive Pressure Breathing on Cardiac Output in Man. Am. J. Physiol. 152: 162 (1948).

30. Maloney, J. V.; Elam, J. O.; Handford, S. W.; Balla, G. A.; Eastwood, D. W.; Brown, E. S.; \& Ten Pas, R. H. Importance of a Negative Pressure Phase in Mechanical Respirators. J. Amer. M.A. 152: 212 (1953).

31. Blatr, D. A., Glover, W. E., \& Kidd, B. S. L. The Effect of Continuous Positive and Negative Pressure Breathing upon the Resistance and Capacity Blood Vessels of the Human Forearm and Hand. Clin. Sci. 18: 9 (1959).

32. Sieker, H. O., Gauer, O. H., \& Henry, J. P. The Effect of Continuous Negative Pressure Breathing on Water and Electrolyte Excretion by the Human Kidney. J. Clin. Invest. 33: 572 (1954).

33. Rodpie, I. C., \& Shepherd, J. T. Receptors in the High Pressure and Low Pressure Vascular Systems: Their Role in the Reflex Control of the Human Circulation. Lancet 1: 493 (1958).

34. Ernsting, J. The Effect of Raised Intrapulmonary Pressure upon the Distensibility of the Capacity Vessels of the Upper Limb. J. Physiol. (Lond.) 197: 52P (1957).

35. DaLy, I. DE B. Intrinsic Mechanisms of the Lung. Quart. J. Exper. Physiol. 48: 2 (1958).

36. Aviado, D. M., JR., Ling, J. S., \& Schmidt, C. F. Effects of Anoxia on Pulmonary Circulation: Reflex Pulmonary Vasoconstriction, Am. J. Physiol. 189: 253 (1957). 
37. Fahri, L. E., \& Rahn, H. Gas Stores of the Body and the/Unsteady State. J. Appl. Physiol. $7: 472$ (1955).

38. Austen, F. K., Carmichael, M. W., \& Adams, R. D. Neurologic Manifestationsl of Chronic Pulmonary Insufficiency. New Eng. J. Med. 25\%: 579* (1957).

39. Scurr, C. F. Carbon Dioxide Retention Simulating Curarization. Brit. Med. J. 1: 565 (1954).

40. Fairley, H. B., Waddell, W. G., \& Bigelow, W. G. Hypothermia for Cardiovascular Surgery: Acidosis in the Rewarming Period. Brit. J. Anaesth. $29: 310$ (1957).

41. Mushin, W. W., Rendell-Baker, L., \& Thompson, P. W. Automatic Ventilation of the Lungs. Oxford: Blackwell (1959).

42. CoOper, E. A., \& PASk, E. A. A Bag for Measuring Respiratory Volumes. Lancet 1:369 (1960).

43. Salem, H., Lucas, G. H. W., \& LuCas, D. M. Saran Plastic Bags as Containers for Breath Samples. Canad. M.A.J. 82:-682 (1960).

44. Wright, B. M. A Respiratory Anemometer. J. Phýsiol. (Lond.) 127: 25P (1955).

45. Davenport, H. W. The ABC of Acid-Base Chemistry, 4th edition. Chicago: Univ. of Chicago Press (1958).

46. Riley, R. L.,'Prommel, D. D., \& Franke, R. L. A Direct Method of Determination of Oxygen and Carbon Dioxide Tension in Blood. J. Biol. Chem. 161: 621 (1945).

47. Dornette, W. H. L., \& Brechner, V. L. Instrumentation in Anesthesiology. Philadelphia: Lea \& Ferbiger (1959).

48. Peters, J. P., \& Van Slyke, D. D. Quantitative Clinical Chemistry: II, Methods. Baltimore: Williams \& Wilkins (1932).

49. Astrup, R. A Simple Electrometric Technique for the Determination of Carbon Dioxide Tension in Blood and Plasma, Total Content of Carbon Dioxide in Plasma and Bicarbonate Content in "Separated" Plasma at a Fixed Carbon Dioxide Tension. Scand. J. Clin. Lab. Invest. 8: 33 (1956).

50. Plesch, J. Hämodynamische Studien. Z. exp. Path. Ther. '6:380 (1909).

51. Hackney, J. D., Sears, C. H., \& Collier, C. R. Estimation of Arterial $\mathrm{CO}_{2}$ Tension by Rebreathing Technique. J. Appl. Physiol. 12: 425 (1958).

52. Campeell, E. J. M., \& Howell, J. B. L. Simple Rapid Methods of Estimating Arterial and Mixed Venous $\mathrm{pCO}_{2}$. Brit. Med. J. 1: 458 (1960).

53. Camprell, E. J. M., \& Howell, J. B. L. The Rebreathing Method of Estimating Arterial and Mixed Venous $\mathrm{CO}_{2}$ Tension. Brit. J. Dis Çhest 54:137 (1960).

54. Scholander, P. F. Analyzer for Accurate Estimation of Respiratory Gases in One Half Cubic Centimeter Samples. J. Biol. Chem. 167: 235 (1935).

55. Fowler, R. C. Rapid Infrared Gas Analyzer. Rev. Scient. Instruments 20: 175 (1949).

56. Dubois, A. B.; Fowler, R. C.; SAFfer, A.; \& FENN, E. O. Alveolar Carbon Dioxide Measurements by Expiration into the Rapid Infrared Gras Analyzer. J. Appl. Physiol. 4: 526 (1951).

57. Collier, C. R., Affeldt, J. E., \& Farr, A. F. Continuous Rapid Infrared Carbon Dioxide Analysis. J. Labi \& Clin. Med. 45: 526 (1955).

58. Elam, J. O., Brown, E. S., \& Ten Pas, R. H. Carbon Dioxide Homeostasis During Andesthesia: Instrumentation. Anesthesiology 16: 876 (1955).

59. Engel, H. C., \& IbSEN, B. Continuous Carbon Dioxide Measurements in Respiratory Air During Anaesthesia in Thoracic Operations. Acta Clin. Scand. 104: 313 (1952).

60. Nunn, J. F. The Dräger Carbon Dioxide Analyzer. Brit. J. Anaesth. \$0: 264 (1958).

61. Ravin, H. A., \& Stern, M. Bedside Measurement of Alveolar Carbon Dioxide Tension. New Eng. J. Med. 259: 811 (1958).

62. Capel, L. H., \& Hodgson, D. C. 'Simple Automaticl Sampler of End-expired Air for Pressure Breathing Lancet 2: 609 (1956).

63. WeIner, R. S., \& CoOper, P. The Use of "Arterialized" Blood for the Determination of Arterial $\mathrm{O}_{2}$ and $\mathrm{CO}_{2}$ Tensions. J. Thorac. Surg. $30: 683$ (1955).

64. Brooks, D., \& WynN, V. Use of Venous Blood for $\mathrm{pH}_{\text {! }}$ and Carbon Dioxide Studies. Lancet $1: 227$ (1959). 
65. Dubois, A. B., Britt, A. G., \& Fenn, W. 0 . Alveolar $\mathrm{CO}_{2}$ during the Respiratory Cycle. J. Appl. Physiol. 4: 535 (1952).

66. Nunn, J. F., \& Pincock, A. C. A Time-phased End Tidal Sampler Suitable for Use during Anaesthesia. Brit. J. Anaesth. 29: 98 (1957).

67. Smith, A. C., Schuster, E., \& Spalding, J. M. K. An End-tidal Air Sampler. Lancet 1: 277 (1959).

68. Comroe, J. H., J R., \& Dripps, R. D. The Physiological Basis for Oxygen Therapy. Springfield: Thomas (1953).

69. Pauling, L., Wood, R. E., \& Sturdivant, J. H. An Instrument for Determining Partial Pressure of Oxygen in a Gas. Science 103: 338 (1946).

70. Wood, E. H. A Single Scale Absolute Reading Ear Oximeter. Proc. Staff Meet., Mayo Clinic 25: 384 (1950).

71. Zjilstra, W. G. Fundamentals and Applications of Clinical Oximetry. Assen, Netherlands: Van Gorcum (1953).

72. Catron, W. T. Physical Methods in Physiology. London: Pitman (1957).

73. Van Slyke, D. D., \& Neill, J. M, The Determination of Gases in Blood and Other Solutions by Vacuum Extraction and Manometric Measurement. J. Biol. Chem. 61: 523 (1924).

74. Smart, R. H., Davenport, C. 'K., \& Pearson, G. W. Intermittent Positive Pressure Breathing in Emphysema and Chronic Lung Diseases. J.A.M.A. 150: 1385 (1952).

75. Segal, M. S.; Salamona, A.; Dulfano, M. J.; \& Herschfus, J. A. Intermittent Positive Pressure Breathing. New Eng. J. Med. 250: 225 (1954).

76. Mörch, E. T., SAXTon, G. A., \& Grsh, G. Artificial Respirationn via the Uncuffed Tracheostomy Tube. J.A.M.A. 160: 864 (1956)

77. Mörch, E. T., \& SAxton, G. A. Tracheostomy Tube Connectors. Anesthesiology. 17: 366 (1956).

78. Avery, E. E., Mörch, E. T., \& Benson, D. W. Critically Crushed Chests. J. Thorac. Surg. 82: 291 (1956).

79. Spalding, J. M. K., \& Smith, A. C. A New Tracheotomy Tube. Lancet 2: 1247 (1956).

80. Bullough, J. Tracheostomy Tube and Connections for Patients Having Intermittent Positive Pressure Respiration. Lancet 2: 372 (1957).

81. Dreifuss, F. E., Hurwitz, L. J., \& John, C. Polyneuritis Requiring Artificial Respiration. Lancet 2: 59 (1957).

82. Barach, A. L., Beck, G. J., \& Smith, W. H. Mechanical Production of Expiratory Flow Rates Surpassing the Capacity of Human Coughing. Am. J. Med. Sci. 226: 241 (1953).

83. Greene, N: M. Fatal Cardiovascular and Respiratory Failure Associated with Tracheotomy. New Eng. J. Med. 261: 846 (1959).

84. Davis, H. S., Kretchmer, H. E., \& Bryce-Smith, R. Advantages and Complications of Tracheotomy. J.A.M.A. 15s: 1156 (1953).

85. Nelson, T. G. Tracheotomy: Clinical and Experimental Study. Pt. II. Am. Surg. 23: 750 (1957).

86. Talbot, T. R., JR., Quimby, E. H., \& Barach, A. L. Method of Determining Site of Retention of Aerosols Within Respiratory Tract of Man by Use of Radioactive Sodium. Preliminary Report. Am. J. M. Sc. 214: 585 (11947).

87. Marshall, J., \& Spalding, J. M. K. Humidification in Positive Pressure Respiration for Bulbospinal Paralysis. Lancet 2: 1022 (1953).

88. Fairley, H. B. The Selection of a Mechanical Ventilator. Canad. Anaesth. Soc. J. 6:219 (1959).

89. Ruben, H., \& Ruben, A. Apparatus for Resuscitation and Suction. Lancet 2: 373 (1957).

90. Elam, J. O., KerR, J. H., \& JANNEY, C. D. Performance of Ventilators: Effects of Changes in Lung-Thorax Compliance. Anesthesiology 19:56 (1958).

9r. BJork, V. O., \& Engsrrom, C. G. The Treatment of Ventilatory Insufficiency After Pulmonary Resection with Tracheostomy and Prolonged Artificial Ventilation. J. Thorac. Surg. 30: 356 (1955). 
92. Nunn, J. F. The Anaesthetist and the Emphysematous Patient. Brit. J. Anaesth. 30: 134 (1958).

93. Van Bergen, F. H.; Buckley, J. J.; Weatherhead Đ. S. P.; Schultz, E. A.; \& Gordon, J. R. A New Respirator. Anesthesiology. 17: 708 (1956).

94. Dinnick, O. T. Modified Beaver Respirator: The Application of Negative Phase. Brit.|J. Anaesth. $81: 554$ (1959).

95. Sxmons, A. Physiotherapy and the Radcliffe Pump. Physiotherapy (July, 1958).

96. Opie, L. H., \& Spaloing, J. M. K. Chest Physiotherapy During I.P.P. Respiration. Lancet 2: 671 (1958).

97. Opie, L. H., \& Smith, A. C. Tracheobronchial Toilet Through a Tracheostome. Lancet 1 : 600 (1959).

98. Lilly, J. Mental Effects of Reduction of Ordinary Levels of Physical Stimuli. on Intalct Healthy Persons. Psychiat. Res. Reports $5: 1 \div(1956)$.

99. Mendelson, J. H., \& Foley, J. M. An Abnormálity of Mental Function Affecting Patients with Poliomyelitis in a Tank-type Respirator. Tr. Am. Neurol. Assoc. 134-136 (1956).

100. Lassen, H. C. A.; Henriksen, E.; Neukirch, F.; \& Kristensen, H. S. Treatment of Tetanus: Severe Bone Marrow Depression After Prolonged Nitrous Oxide Anaesthesła. Lancet 1: 527 (1956).

101. Smith, S. M.; Brown, H. O.; Toman, J. E. P.; \& Goodman, 'L. S. The Lack of Cerebral Effects of d-Tubocurarine. Anesthesiology. 8:1 (1947).

102. Denny-Brown, D. E. Effect of Poliomyelitis on the Function of the Motor Neurone. Arch. Neurol. and Psychiat. 64: 1 (1950).

103. Plum, F., \& Whedon, G. D. Rapid Rocking Bed: its Effect on Ventilation of Poliomyelitis Patients with Respiratory Paralysis. New Eng. J. Med. 245: 235 (1951).

104. Cameron, G. S.; Scott, J. W.; Jousse, A. T.; \& Botrerell, E. H. Diaphragmatic Respiration in Quadraplegic Patient and Effect of Position on his Vital Çapacity. Ann. Surg. 141: 451 (1955).

105. Nilsson, E. On Treatment of Barbiturate Poisoning: a Modified Clinical Aspect. Acta med. Scand., Suppl. 253 (1951).

106. WISE, R. P. Treatment of Barbiturate Poisoning. Brit. J. Anaesth. $30: 533$ (1958).

107. Russell, W. R. Poliomyelitis. 1st edition. London: Arnold (1952).

108. Denny-Brown, D. E. Clinical Problems in Neuromuscular Physiology. Am. J. Med. $15: 368$ (1953).

109. Walshe, F. M. R., \& Ross, J. The Clinical Picture of Minor. Cord Lesions in Association with Injuries of the Cervical Spine: with Special Reference to the Diagnostic and Localizing Value of the Tendon Reflexes of the Arm (Inversion of the Radial Reflex). Brain. 59: 277 (1936).

110. Symonds, C. The Interrelation of Trauma and Cervical Spondylosis in Compression of the Cervical Cord. Lancet 1: 451 (1953).

111. Van Bergen, F. H., \& Buckley, J. J. The Management of Severe Systemic Tetanus: Anesthesiology 13: 599 (1952).

112. Smith, A. C., Hill, E. E., \& Hopson, J. H. Treatment of Severe Tetanus with d-Tubocurarine Chloride and Intermittent Positive Pressure Respiration. Lancet 2: 550 (1956).

113. Woolmer, R., \& Cates, J. E. Succinylcholine in the Treatment of Tetanus. Lancet 2: $808(1952)$.

114. Shackleton, P. The Treatment of Tetanus: The Role of the Anaesthetist. Lancet 2: 155 (1954).

115. Creech, O., Glover, A., \& Ochsner, A. Tetanus. Evaluation of Treatment at Charity Hospital, New Orleans, Louisiana. Amer. Surg. 146: 369 (1957).

116. Alhady, S. M. A.; Bowlek, D. P.; Reid, H. A.; \& Scott, L. T. Total Paralysis Regime in Severe Tetanus. Brit. Med. J. 1:540 (1960).

117. Ablett, J. J. L. Tetanus and the Anaesthetist: A Review of the Symptomatology and the Recent Advances in Treatment. Brit. J. Anaesth. 28: 258 (1956).

118. KELLY, R. E, \& LAWRENCE, D). R. Effect of Chlorpromazine on Convulsions of Experimental and Clinical Tetanus. Lancet 1: 118 (1956). 
119. Cole, A. C. E., \& Robertson, D. H. H. Chlorpromazine in the Management of Tetanus. Lancet 2: 1063 (1955).

120. Perlstein, J. A. Control of tetanus spasms by injection of meprobamate. J.A.M.A. 170: 1093 (1959).

121. Kellaway, G. Acute Anoxic Cardiac Failure in Pulmonary Heart Disealse. Lancet 2: 768 (1959).

122. Jameson, A. C., Ferrier, M. I., \& Harvey, R. M. Some Effects of Mechanical Respirators upon Respiratory Gas Exchange and Ventilation in Chronic Pulmonary Emphysema. Am. Rev. Resp. Dis. 80: 510 (1959)|.

123. MacIver, I. N., Frew, I. J., \& Matheson, J. G. The Role of Respiratory Insufficiency in the Mortality of Severe Head Injuries. Lancet 1: 390 (1958).

124. Barretr, N. R. Early Treatment of Stove-in-chest. Lancet 1: 293 (1960).

125. SANDiford, H. B. C. Emergency Treatment of Respiratory Failure in Poliomyelitis. Lancet 2: 823 (1957).

\section{NOTICE}

Reprints of the Review Article on

\section{THE MANAGEMENT OF THE PATIENT WITH RESPIRATORY INSUFFICIENCY}

by H. Barrie Fairley, M.B., B.S., F.R.A.R.C.S., and

R. A. Chambers, M.D., M.R.C.P.

are available on application to

The Canadian Anaesthetists' Society Journal,

178 St. George Street, Toronto 5, Canada.

Price: 50 cents per copy 